\title{
Technology-mediated workplace language training: Developing and assessing a module for a blended curriculum for newcomers
}

by

Gillian McLellan

\begin{abstract}
A thesis submitted to the Faculty of Graduate and Postdoctoral Affairs in partial fulfillment of the requirements for the degree of
\end{abstract}

Masters of Arts

in

Applied Linguistics and Discourse Studies

Carleton University
Ottawa, Ontario

(C) 2019, Gillian McLellan 


\begin{abstract}
Canadian newcomers with low proficiency in English or French face challenges in the workforce (Kustec, 2012). While language classes provide workplace language training, some newcomers are unable to attend face-to-face classes (Shaffir \& Satzewich, 2010), suggesting a need for outside-the-classroom occupation-specific language training. Technology has been advantageous for second language learning outside the classroom (Stockwell, 2007), with mobile-assisted language learning affording learners greater control over their learning (Yang, 2013).

As part of a larger project, this thesis presents the development and assessment of a technology-mediated task-based module providing workplace-linguistic support on mobile devices, enabling learners to access language instruction when and as needed. The modules were assessed by newcomers of high-beginner English proficiency employed in customer service $(n=4)$ and their teachers $(n=4)$. Results confirm benefits of the approach in providing instruction meeting participant needs, ensuring opportunities for individualized training. Implications for designing and implementing technologymediated modules are discussed.
\end{abstract}

Keywords: newcomers, workplace language training, mobile-assisted language learning, technology-mediated task-based language teaching 


\section{Acknowledgements}

This thesis could not have been done without the help of many individuals.

First, thank you to Immigration, Refugees and Citizenship Canada for funding this project. Thank you to the employment support organization for all of their help organizing the workplace observations and recruiting participants. Thank you to the participants who were generous enough to let me observe them at their place of work, and the participants who gave up their time to take part in this study.

Thank you to my supervisors Dr. Eva Kartchava and Dr. Michael Rodgers for everything that they have done for me over the last two years. From sharing their insight to providing encouragement, I could not have completed this program without their guidance, patience, and support.

Throughout the development of this project, I have had the opportunity to work with a wonderful research team. Thank you to Alexis, Fatima, Neil, and Rose for all of their help and hard work, and for kindly agreeing to act in the module videos. It was no easy task!

I must also thank Alex who, over the last two years, has been a mentor, colleague, and friend. We are so lucky to have someone so dedicated on this project, and I am so lucky to have such a supportive friend.

Finally, thank you to all of my friends and family near and far. I am especially grateful to my dear friend Stéphanie for all of her support. I am so grateful to my mother and brother for their continuous love and support and to my father for helping me navigate the academic world, and for encouraging me to pursue this path. Most importantly, thank you to Luke for his constant patience, understanding, and love. 


\section{Table of Contents}

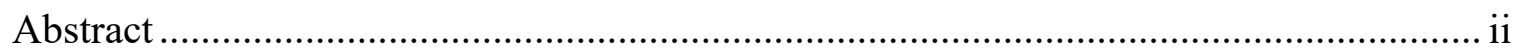

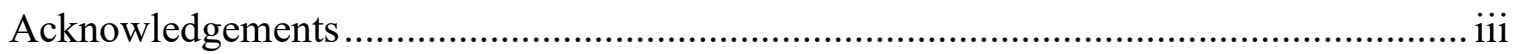

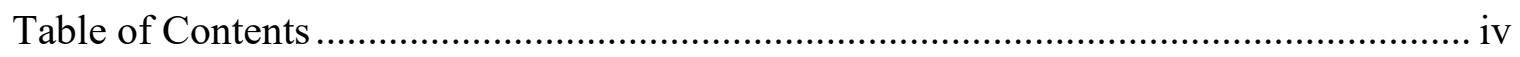

List of Tables .................................................................................................... vii

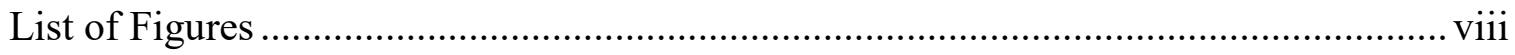

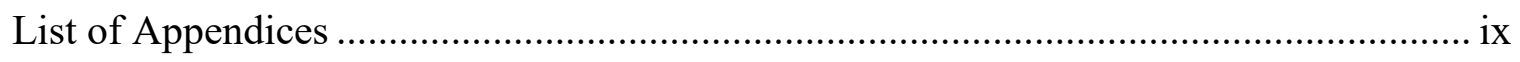

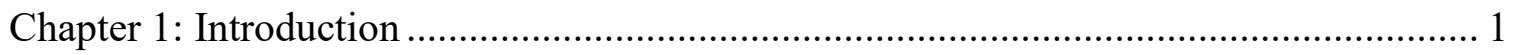

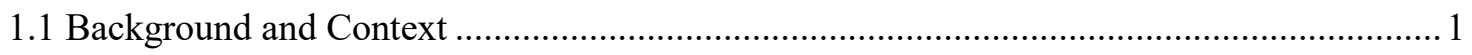

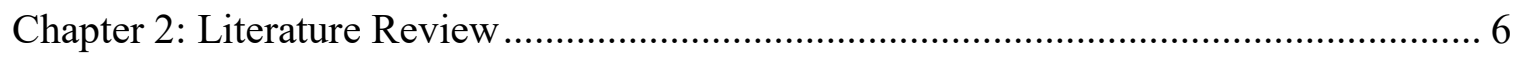

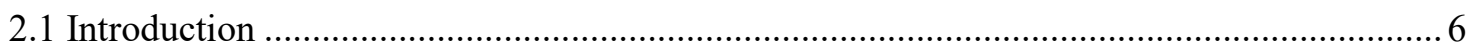

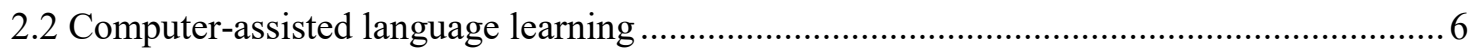

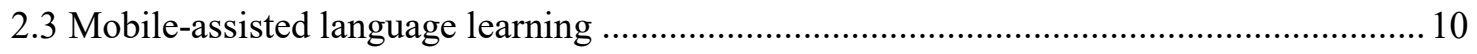

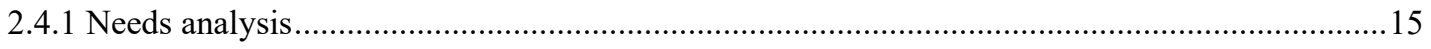

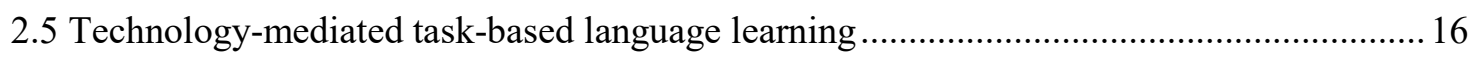

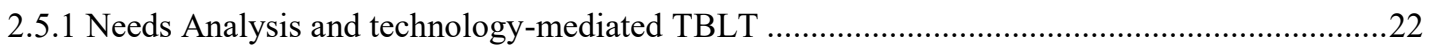

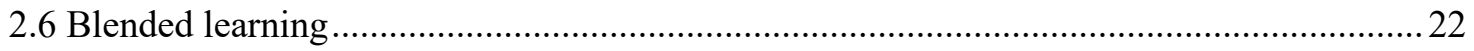

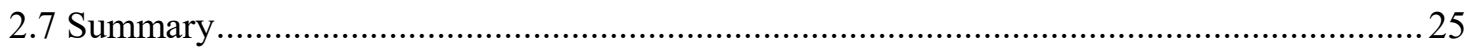

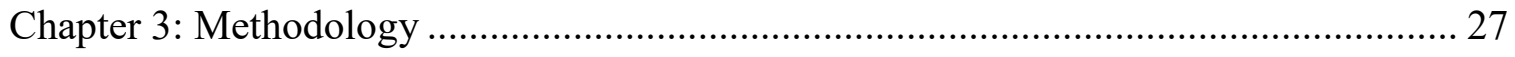




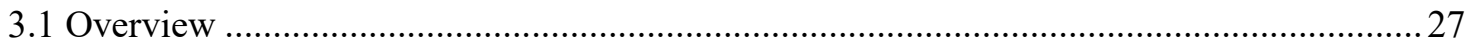

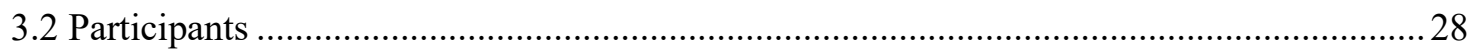

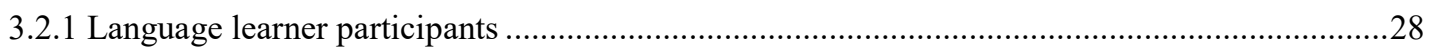

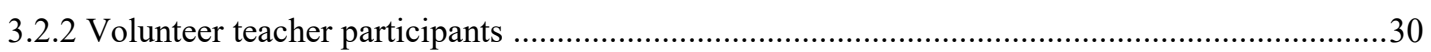

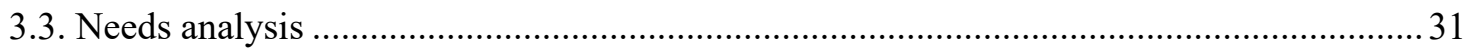

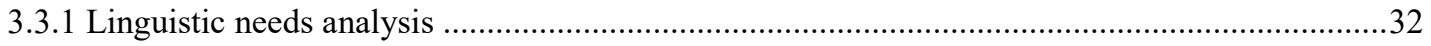

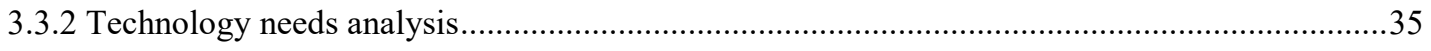

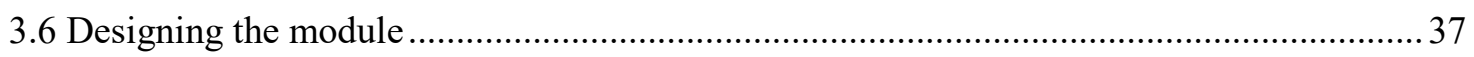

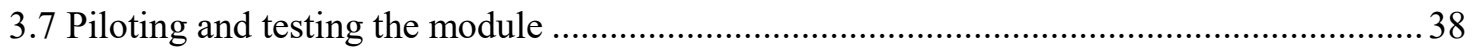

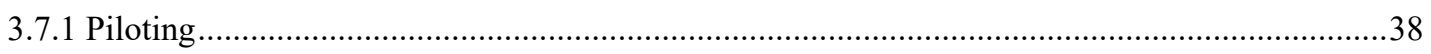

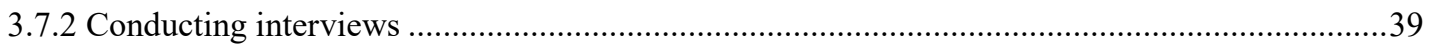

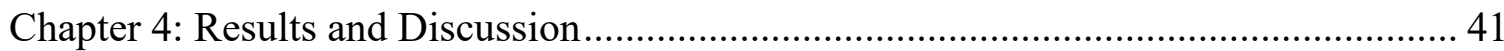

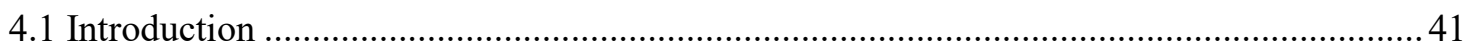

4.2 Research question 1: Linguistic and technological needs of learners.............................. 41

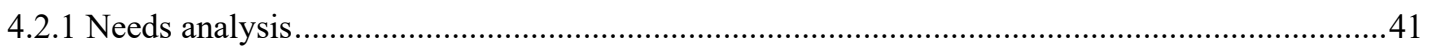

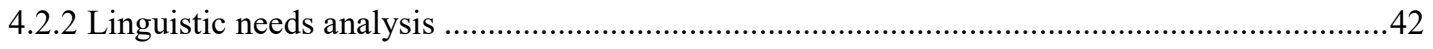

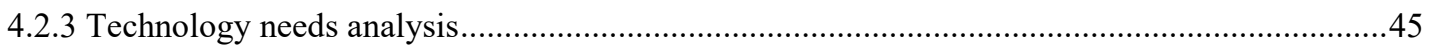

4.3 Research question 2: Incorporating learner needs into a technology-mediated module...... 48

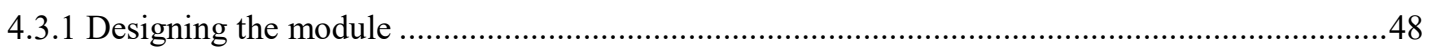

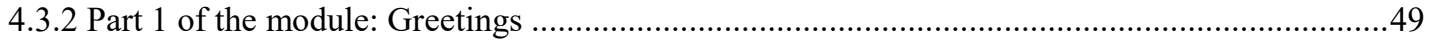

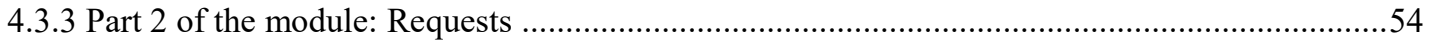

4.4 Research question 3: Perceived module effectiveness by learners and teachers .................63

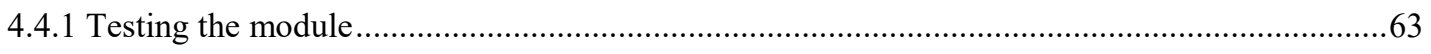

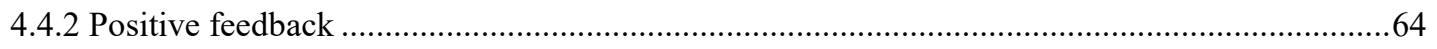


Chapter 5: Conclusion.

5.1 Introduction .72

5.2 Pedagogical implications .72

5.3 Limitations .75

5.4 Future research directions .78

5.5 Conclusion .81

References 83

Appendices.

Appendix A Data collected from textbooks and online resources. .99

Appendix B Data from workplace observations. 103

Appendix C Guiding interview questions...... 108

Appendix D Ethics clearance 109 


\section{List of Tables}

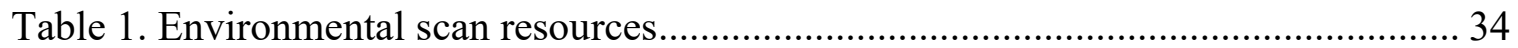

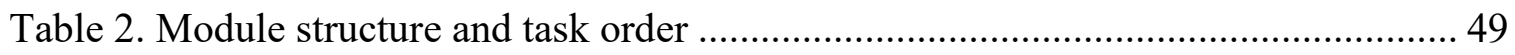




\section{List of Figures}

Figure 1. Example of a greetings contextualization question .................................. 50

Figure 2. Example of greetings language practice ............................................... 51

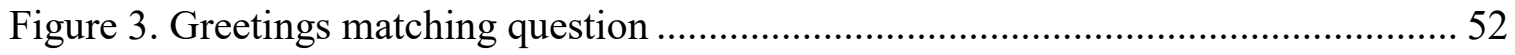

Figure 4. Greetings prediction task with feedback ................................................. 54

Figure 5. Requests narrative for contextualization ............................................... 55

Figure 6. Example of requests language practice .................................................. 57

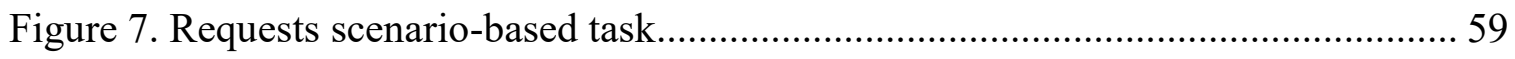

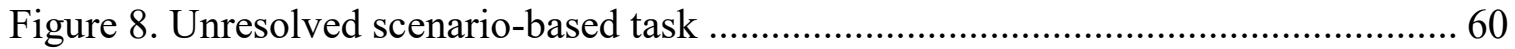




\section{List of Appendices}

Appendix A Data collected from textbooks and online resources ................................ 99

Appendix B Data from workplace observations ..................................................... 103

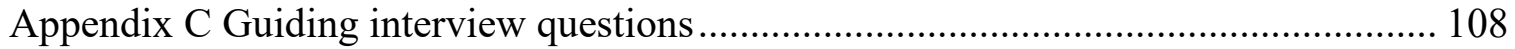

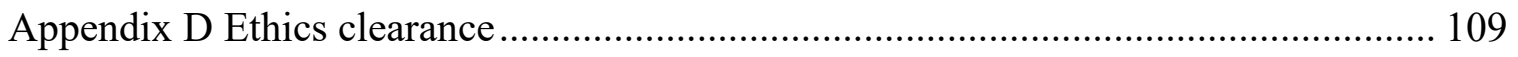




\section{Chapter 1: Introduction}

\subsection{Background and Context}

Newcomers to Canada have identified employment as their number one priority (Kustec, 2012). However, while being the top priority, entering the Canadian workforce has also been identified as one of the greatest challenges faced by newcomers to Canada (George, 2002; Reitz, 2007). A repeatedly identified barrier to employment is insufficient knowledge of either English or French (Lochhead \& Mackenzie, 2005; Reitz, 2007), suggesting a need for workplace language training (Murphy, 2010). This need has also been conveyed by newcomers, who have expressed frustration at not being able to demonstrate the workplace skills they already possess due to not being able to communicate effectively (Lochhead \& Mackenzie, 2005). However, while workplace language is often included in second language (L2) classroom curricula, these face-toface classes are not always accessible to L2 learners. Challenges such as maintaining employment and limited access to childcare prevent some learners from being able to consistently attend language classes (Shaffir \& Satzewich, 2010), resulting in a group of newcomers not receiving the linguistic support they need.

This thesis is part of a larger project that aims to develop a ten-module program hosted on a digital platform, targeting a particular segment of the population, whose L2 education has, until recently, been largely neglected and only peripherally supported. Each of the ten modules will focus on a different aspect or theme of workplace language. Specifically, the linguistic content of these modules will focus on language used by individuals employed in the customer service sector. For the purposes of this project, customer service refers to any job in which an employee directly interacts with customers 
for the purposes of providing a service or assistance (such as working as a cashier). Within the scope of this larger project, the research described in this thesis serves as a "pilot" for the development of the ten modules. This thesis will explore the development of the first of the modules, focused on theme of greetings and requests. This first module will directly influence the remaining nine modules by identifying a computer-assisted language learning (CALL) platform on which the ten modules will be hosted, as well as the overall structure and design of the modules. As such, this thesis explores the development and subsequent piloting and implementation of this one module, and the steps taken to ensure that it is grounded in both research and pedagogy while addressing the needs of a specific group of learners.

The work described in this thesis was done in partnership with a communitybased employment support program for newcomers. A number of community employment support programs have been developed to aid Canadian newcomers by assisting them with finding and maintaining employment (Immigration, Refugees and Citizenship Canada, 2019). While some of the programs provide career-planning services, often accompanied by face-to-face occupation-specific language training classes (Ontario Council of Agencies Serving Immigrants, 2017), other programs offer networking opportunities and employment partnerships alongside language training that is either offered face-to-face or that uses online language learning options (Government of Saskatchewan, 2019; S.U.C.C.E.S.S., 2019). Services provided are tailored to the Canadian context and are designed specifically for newcomers entering the Canadian workforce. For example, some programs also offer guidance about Canadian culture and 
customs alongside language instruction in order to facilitate integration in the workplace (English at Work, 2018).

One such employment support program is the focus of this investigation. As part of this program, newcomers are paired with an employer in various sectors such as hospitality, various trades, and customer service. This program is specifically designed to support newcomers with limited work experience and limited proficiency in English and provides newcomers with access to some language training. Newcomers are matched with a volunteer teacher who meets with them one-on-one and face-to-face on a weekly basis for three hours. The volunteer teacher determines what materials are to be used during these sessions, but the predominant focus is workplace language. The overall goal of this program is to assist newcomers in developing workplace-specific language skills that allowing them to participate in Canadian society.

While this program does already provide some workplace language training, a need for additional outside the classroom language training (i.e., online) was identified due to the learners' limited availability to attend regularly scheduled, face-to-face classes because of their variable work schedules. As such, it was determined that more occupation-specific (i.e., customer service) language training that addresses the specific needs of this group of learners outside the classroom using an online platform was needed. Specifically, this additional training was provided through the development of an online program, one unit of which is described here. It should be noted that this language training is not intended to replace existing face-to-face instruction with the volunteer teachers but is instead designed to augment and support the existing training as part of a blended curriculum. The current face-to-face instruction with volunteer teachers provides 
opportunities for learners to interact with native speakers and to ask questions and express their needs (Blake, Wilson, Cetto, Pardo-Ballester, 2008). However, face-to-face learning alone does not address the need for the adaptability that outside-the-classroom mobile learning affords, including anytime-anywhere access. Newcomers working in customer service require flexible, outside-the-classroom learning that does not interfere with their work schedules. They also require authentic, meaningful linguistic knowledge that can be learned online. This calls for the use of approaches such as technologymediated task-based language teaching (TBLT), which is known for providing learners with authentic and meaningful language though the use of technology, and mobileassisted language learning (MALL), which is known for providing learners with flexible outside-the-classroom learning. These approaches will be explored as part of the development of the module.

\subsection{Organization of thesis}

In what follows, the pedagogical approaches applied as the framework for this study are discussed, including computer-assisted language learning (CALL), mobileassisted language learning (MALL), task-based language teaching (TBLT), technologymediated TBLT, and blended learning. Next, the method of developing the module is discussed with regards to both module content, through the application of needs analysis, and module design, through the use of a technology-mediated TBLT framework. The completed module was piloted and assessed by program-bound learners and teachers, with interviews conducted to obtain feedback regarding the usability of the pedagogical approach adopted and language used within the module. This piloting and interview 
process is also discussed as part of the methodology of this study. The outcome of the needs analysis and the final module design are also presented, along with the feedback (results) obtained during the interviews. This includes a discussion as to how this feedback has helped shape the overall module design, along with suggestions for modifying the module. This thesis ends with an examination of the pedagogical implications, limitations, and future research directions that this line of investigations might take. 


\section{Chapter 2: Literature Review}

\subsection{Introduction}

The overall goal of this project, guided by the research questions, is to provide an online module that offers workplace linguistic support to newcomers. The development of the module must be pedagogically sound and be based in research. Therefore, this literature review explores existing research that examines the various approaches later applied throughout the development of the module. Computer-assisted language learning (CALL) will be discussed both generally and with a focus on mobile-assisted language learning (MALL). Following this, the pedagogical approach of task-based learning, which is the approach applied in the development of the module, will be explained and reviewed. Next, the application of TBLT with CALL, referred to as technology-mediated TBLT, will be discussed. Lastly, because the module is designed to be a supplement to face-to-face learning as part of a blended curriculum, the background and implementation of a blended approach to second language learning is discussed.

\subsection{Computer-assisted language learning}

Language learning technology is becoming increasingly integrated into the English as a second language (ESL) classroom in a variety of ways, due to continuous technological advancements (Lee \& Egbert, 2016). It should be noted that the use of technology for language learning predates computers, with audio-recording devices being one of the more common earlier tools used (Farr \& Murray, 2016). However, it is computers that led to an increase of technology being used for language learning, and as such there have been significant increases in the use of language learning technology over 
the last 30 years (Farr \& Murray, 2016). This type of language learning technology is commonly referred to as computer assisted language learning (CALL) (Healey, 2016). However, with development of cell phones and tablets, another increasingly common term is mobile-assisted language learning (MALL), which refers to technology used via mobile devices (Godwin-Jones, 2011; Yang, 2013). It should be noted that while MALL is occasionally used as a term separate from CALL, MALL can also be considered a subset of CALL and at times the term CALL is retained when referring to mobile technology (Healey, 2016). For the purposes of this thesis, both the terms CALL and MALL will be used, with CALL referring to technology more generally, and with MALL referring to implementation via mobile devices.

Because CALL refers somewhat broadly to language learning technology (i.e., it does not refer to a specific software or program), it has been applied in various forms and contexts. Originally, CALL was primarily integrated in face-to-face contexts through the use of language labs (Farr \& Murray, 2016). These language labs provided additional opportunities for learners to enhance their listening and speaking skills (Roby, 2004). Further advancements in technology have resulted in increased opportunities for learning due to the increased capabilities of CALL (Farr \& Murray, 2016). For example, when CALL began to appear in L2 classrooms 30 years ago, teachers were often required to reserve a set period of time, often weekly, for learners to use the school's computer lab. However, most classrooms are now equipped with technology, making its use more integrated, while home computers and mobile devices have led to increased use outside the classroom (Blake, 2013; Murray, 2005). 
Blake (2013) asks why L2 practitioners and researchers should consider using technology for language learning. He emphasizes the ability of CALL to provide learners opportunities to engage with the target language that would not otherwise be possible and cites its use as a social tool. Blake considers the use of internet to be the most pervasive when implementing CALL and compares learner use of internet to learn an L2 to the experience of a learner travelling abroad to learn a language. He praises the use of CALL for providing learners with unique exposure to the L2 but does caution that CALL itself is just a tool and that it is the responsibility of researchers and practitioners to explore how to effectively apply it.

When effectively applied, CALL is thought to increase the rate of learning and to make learning more efficient (Blake, 2013). Other proposed benefits to using CALL include providing more opportunities for engaging in an L2 (Chappelle, 2005) and more opportunities for learners to receive input due to the use of audio and other multimedia tools (O’Bryan \& Hegelheimer, 2007). It is often applied in a manner that targets the four linguistic skills of reading, writing, listening, and speaking (Levy, 2009). In a review of existing literature, Stockwell (2007) concludes that the majority of CALL research has been concerned with reading and writing skills, followed by listening, with speaking being focused on the least. By examining language skills and areas, it can be seen how CALL has been used to enhance various aspects of second language acquisition. This suggests that these skills can be enhanced through the development of the module.

Learner and teacher perceptions of CALL have also been found to influence its use (Kim, 2008; Plonsky \& Zeigler, 2016). Insight can be gained by examining teacher and student perceptions of technology, including how to implement successfully the 
technology in an L2 context (Egbert, Paulus \& Nakamichi, 2002). Exploring this can help identify obstacles that prevent teachers and students from using technology, as well as how it can be more effectively implemented in a classroom (Plonsky \& Zeigler, 2016). Lasagabaster and Sierra (2010) further emphasize the importance in exploring student perceptions of CALL, as students will be using the software more frequently than teachers. In terms of learner and teacher perceptions of CALL, the overall response has been positive (Hsu, 2011). The usability of the software employed has been considered to directly correlate with both learner and teacher perceptions (Egbert et al., 2002; Kim, 2008; Lasagabaster \& Sierra, 2010). Software that is more challenging or that requires extensive training to use is often perceived as frustrating and is reported to be less likely to be used by teachers (Egbert et al., 2002), demonstrating the importance of selecting software that it easy to use. Furthermore, a student's frequency of use of a specific technology has been connected to the student's level of familiarity and the ease with which the technology can be used (Lasagabaster \& Sierra, 2010).

The use of CALL has changed significantly since it was first implemented due to advancements in technology. It has been shown to allow learners to improve the four skills of reading, writing, listening, and speaking, and has been well received by both learners and teachers, suggesting it is an effective approach to language learning. The benefits to using CALL have been observed both inside and outside the classroom, with the increasing use of mobile technology (Kulkuska-Hulme, 2007) resulting in technology being used increasingly outside the classroom under the term MALL. 


\subsection{Mobile-assisted language learning}

Technology has been used as a tool for L2 language learning outside the classroom with success (Chen, 2013; Stockwell, 2010). Its capacity for use outside the classroom, through the use of mobile assisted language learning (MALL), suggests that there is an opportunity to host an online module aimed for use by newcomers in the workforce who are not able to attend language classes.

The use of MALL has resulted in the development of technology that targets language relevant to specific (non-classroom) environments, including the workforce, with positive results. Ally, McGreal, Schafer, Tin, and Cheung (2007), for example, found that student perceptions of mobile-based workplace language training were positive. MALL has also been praised for its flexibility of use, including use outside the classroom (Yang, 2013). Students reported that the flexibility and availability of mobile language learning technology made them more likely to practice their English outside of the classroom (Godwin-Jones, 2011). Kukulska-Hulme and Shield (2008) also found this to be the case, a conclusion that was influenced by the fact that a significant number of students reported having access to a personal cell phone. Stockwell (2010) observed that the convenience of mobile technology was advantageous since many students would use technology in what he refers to as "dead time" (p. 9). In other words, students were using technology at times where they were waiting for something (e.g., an appointment) or commuting to work or school. This enabled students to choose more easily when they would like to practice their language skills and allowed for an easier integration of language practice into their daily lives. The use of MALL has been shown to provide learners with greater control over their own learning and to help encourage learner 
autonomy (Guichon \& McLornan, 2008; Schwienhorst, 2008). Ellis and Bogart (2007) also found that students who use MALL outside of the classroom were able to learn more contextually-relevant and environmentally-specific vocabulary, as there is often little exposure to this type of vocabulary in the classroom. The development of online dictionaries and translators has also led to an increase in students' use of language learning technology outside of the classroom due to the portability that comes with a cellphone (Rahimi \& Miri, 2014).

Kim and Kwon (2012) have also found the use of MALL to be effective in extending learning opportunities to outside the classroom. Like other researchers, they praise the fact that MALL enables learners to access more efficiently learning materials at any time, and any place, and observe that the use of MALL may increase the rate at which learners are able to learn and develop better language skills. However, they caution that in order for MALL to be implemented successfully, MALL material developers must have a thorough understanding of the technological capabilities of the given software and an awareness of learner needs. Knowledge of both software affordances and learner needs can be carried and referred to throughout the development of MALL, guiding both content and design. This is relevant to the current study, which uses knowledge of learner needs and considers these needs throughout the development of the module.

Lee and Egbert (2016) discuss the connection between technology and culture, and note that different cultures may have different practices with regards to technology use. In a classroom with students coming from a variety of cultural backgrounds, this may mean that students have differing perceptions as well as levels of experience with technology (Lee \& Egbert, 2016). This was considered when developing the module for 
this group of learners. All learners reported that they possess a cell phone and know how to use it. They reported feeling comfortable using cell phones and even prefer using them over other types of technology, thus further emphasizing the need for the module to be developed for mobile technology.

While the convenience and portability of mobile devices can make this type of technology an asset (Yang, 2013), one limitation that has been described in particular with regards to MALL is the size of the device (Levy, 2009; Lu, 2008; Stockwell, 2010). Yang (2013) found that the majority of learners consider the size of the device to be an advantage of using MALL. However, some learners felt frustrated at the small screen size and the need to scroll while reading. $\mathrm{Lu}$ (2008) also found that students appear to have more success when using technology that is clear and easy to read and that doesn't require the changing of screens or scrolling. Overall, Yang (2013) notes that students and teachers may have to decide what is a priority or what will work best for the individual. However, the increasing use of cellphones (Kulkuska-Hulme, 2007) suggests that MALL might be a more successful approach than the use of other forms of language learning technology. This, then, speaks to the application of MALL in providing language training to this group of learners. Since the outside-the-classroom component of a blended curriculum is the focus of this study, MALL will be more considered for use within this context. Overall, the capabilities of MALL were deemed desirable for the group of learners for whom this module is intended. Its flexible nature along with the convenience and portability are well-suited to the fact that these learners in customer service work varying hours and own a mobile device (most often, mobile phones) that they engage with frequently. 


\subsection{Task-based language teaching}

Task-based language teaching (TBLT) is a pedagogical approach that provides learners with the opportunity to use the target language authentically (e.g., English for the workplace) by completing tasks (Ellis, 2003; Douglas \& Kim, 2014). It is a form of implicit instruction that draws learner attention to form while learners are engaged in communicating (Ellis, 2005). TBLT has been regarded by some as more effective than other types of teaching (Plews \& Zhao, 2010). Long (2016), in particular, argues that the implicit nature of task-based instruction causes learner knowledge to be more durable and impactful due to it having more depth than other types of teaching. The authenticity of tasks and their connection to the real world are thought to lead to better transfer of linguistic knowledge outside the classroom.

Within TBLT, tasks are considered to be more refined than the more general "activity" (Hunter, 2017). Thornbury (2006) defines an activity as a procedure that learners are required to do at a given point of time, using the target language. The definition of "activity" is quite broad, something which is not the case for tasks. In order for an activity to be classified as a task, certain criteria must be met. Ellis (2003) discusses four criteria that can be used to define a task. A task must (1) be meaning focused, (2) have a non-linguistic outcome, (3) require learners to rely on/use their own resources to complete the task, and (4) have some sort of 'gap'. A 'gap' can refer to gaps between learner interlanguage (i.e., the learner's current linguistic knowledge) and the target language features (i.e., the desired linguistic knowledge) (Long, 2016). There are a variety of tasks that are commonly used when implementing a task-based curriculum. 
Common tasks include problem-solving tasks, decision-making tasks, and role-plays (Long, 2016). The overall task design allows for learners to use the target language in a natural way (Ellis, 2005) and to connect the language used in the task to the real world (Long, 2016). As Doughty and Long (2003) state, TBLT promotes "learning by doing" (p. 58).

In terms of implementing tasks, the general task structure does vary. However, a commonly used structure for tasks involves the use of a task cycle, with different frameworks for task cycles having been developed (see e.g., Nunan, 1989; Willis, 1996). A common task cycle developed by Willis and Willis (2007) consists of a pre-task, task body, and post-task. Pre-tasks can be used to prepare or prime learners for the task and often introduce learners to the topic of the task. The task body (sometimes referred to as the "during-task" phase [Ellis, 2003]) is the main component of the task cycle and is where learners complete tasks designed using criteria such as those described by Ellis. The post-task acts as a follow-up to the task and provides learners opportunities to revisit or reflect on the language used in the task (Willis \& Willis, 2007). While this structure is often used within the classroom for face-to-face learning, the pre-task and post-task elements of TBLT are not considered obligatory - only the task body is required (Ellis, 2003). Ziegler (2016) notes that when applying TBLT in the context of CALL, the definition of a task may have to be expanded upon in order to capitalize on the capabilities of the given software. However, even if the task is not presented in a pre-task, task, post-task format, certain principles regarding task structure are still applied, such as first preparing learners for the task (such as through contextualization [Beglar \& Hunt, 2002]) and then progressively increasing the cognitive demand on learners by making the 
tasks increasingly challenging while providing learners opportunities for language practice. This allows for learners to use problem-solving skills and activates social, behavioural, and cognitive mechanisms. Follow-up can also still be done by having learners build on the knowledge they used previously in the task to complete something new, further activating cognitive mechanisms. This is relevant to the current study, which uses TBLT principles, first preparing learners for the tasks and building learner schemata, and next providing learners with opportunities for language practice that, as they progress through the module, place an increased cognitive demand on the learners and require them to use problem-solving skills.

\subsubsection{Needs analysis}

Another important component of TBLT is the concept of "needs analysis". Needs analysis is a tool that allows for the assessment of learner needs. It is commonly done as part of a task-based approach, with Long (2015) identifying it as the first step in curriculum development. He states that it is important to assess learners' linguistic needs since they are often diverse. He asserts that conducting a needs analysis allows for the identification of goals and communicative needs, which, in turn, enables appropriate material design and delivery. The ultimate outcome of the needs analysis is to feed task development. A needs analysis can be done in a variety of ways. It can involve using questionnaires to survey the learners or conducting interviews to consult learners as to their needs (González-Lloret, 2014). Long (2005) describes a different approach to needs analysis. He discusses exploring the context of learning to identify what language is needed for learners to communicate in said context. He observes that the results of most 
needs analysis resemble a sort of list of "decontextualized structural items" (p. 23) that lend themselves to being input for task design. The importance of needs analysis is explored by Benesch (1996), who emphasizes that to omit needs analysis when developing materials is to narrow learner capabilities by adapting the learner to fit a particular form. Furthermore, she equates needs analysis with a learner-centred approach to teaching; the use of needs analysis ensures that focus remains on the learners and their goals. Long (2005) also condemns omitting needs analysis, stating that if a needs analysis is not done, language learning becomes "one type fits all", therefore lacking the specificity to address language needed for a given context, such as academia or the workplace. As this study explores the linguistic needs of the learners within the context of the workplace, needs analysis will feature significantly in an exploration as to the context and design of the module.

\subsection{Technology-mediated task-based language learning}

When implementing the use of CALL, researchers have explored the application of various second language acquisition (SLA) pedagogical frameworks in order to ensure that the design of CALL is grounded in research (Doughty \& Long, 2003). TBLT is one of these frameworks, and it has been applied by various researchers (e.g., Chapelle, 2001; Doughty \& Long, 2003; Egbert \& Yang, 2004; González-Lloret \& Ortega, 2014). Ziegler (2016) describes the two as "ideal partners in a reciprocal relationship" (p. 137). She advocates for the use of a TBLT framework when implementing CALL and uses this approach as a method to ground CALL contexts in research. 
The desire to encourage learner autonomy and individualized learning speaks to the application of task-based language teaching in this context. This is because TBLT is a goal-oriented pedagogical approach that focuses on the meaningful use/exchange of language to achieve a specific outcome (Willis, 1996). However, the application of the pedagogical approach needs to be discussed within the context of CALL.

Hampel and Hauck (2004) found that the use of TBLT with CALL (termed in this study as "technology-mediated TBLT" [González-Lloret \& Ortega, 2014]) allows for more opportunities for individualized learning. Technology-mediated TBLT takes the underlying principles of TBLT and integrates them into the use of CALL to promote engaged learning (González-Lloret \& Ortega, 2014). Egbert and Yang (2004) outline eight conditions for implementing this approach in a manner that optimizes language learning. These conditions are similar to those developed by Ellis (2003) but are situated within the context of implementing TBLT with technology. These conditions describe the circumstances that Egbert and Yang (2004) consider necessary for technology-mediated TBLT to be successful. Unlike other conditions, Egbert and Yang's conditions consider the motivational aspects of CALL and highlight their importance to efficient and effective language learning. While they propose these conditions for use with CALL, these conditions are focused on what the learner needs within a technology-mediated TBLT framework and not on the technology itself. These conditions state that learners should:

1. have opportunities to negotiate meaning;

2. interact in the target language with an authentic audience;

3. complete tasks that are authentic; 
4. be exposed to varied language;

5. be given enough time to complete the task and receive sufficient feedback;

6. be guided throughout the learning process;

7. complete tasks in a low anxiety environment; and,

8. be supported in their development towards learner autonomy.

Egbert and Yang argue that adhering to these conditions when using a technologymediated TBLT framework to develop tasks will motivate learners, encourage them to take risks, and lead to efficient and effective learning. However, they do note that it is not always possible to adhere to all of the principles and encourage focus on developing tasks that allow for learners to have varied opportunities.

In addition to the conditions proposed by Egbert and Yang, González-Lloret and Ortega (2014) propose criteria for technology-mediated tasks. Their criteria are framed differently than those proposed by Egbert and Yang in that they focus on the tasks and technological elements (such as learner digital literacy skills). These criteria state that:

1. The focus must be on meaning (such as semantic or pragmatic meaning) rather than on form;

2. Tasks must have a communicative purpose that is oriented to the learners' goals (i.e., while the use of desired language is required within the task, it is not itself the goal of the task);

3. Tasks must be learner-centric and allow for learners to use their existing linguistic and non-linguistic resources as well as their digital literacy skills; and must be authentic and reflective of real-world experiences; and 
4. Learners must be given the opportunity to learn through doing as well as the opportunity to reflect on the process.

González-Lloret and Ortega's criteria are similar to Ellis's (2003) criteria for TBLT, but with slight modifications to account for the context of CALL. For example, Ellis (2003) states that tasks should require learners to use their own skills to complete the task. González-Lloret and Ortega (2014) include this in their criteria for technology-mediated TBLT and expand it to include learner digital literacy skills.

Additional research has applied a technology-mediated TBLT framework with success (Lai \& Li, 2011; Lamb, 2004; Ziegler, 2016). Lai and Li (2011), finding, for example, that using a technology-mediated TBLT may allow for the activation of cognitive, behavioural, attitudinal, and social mechanisms that are not activated in traditional face-to-face interactions. They conclude that technology can help promote task-based language development. Sykes (2005) found that such tasks allowed learners to use more complex as well as a wider variety of pragmatic strategies than in face-to-face interactions alone, something Lamb (2004) also found to be the case. Furthermore, research has indicated that the use of technology-mediated TBLT may lead to increased levels of learner motivation and reduced levels of learner anxiety, while increasing learner engagement and participation as well as improving the quality of learner language production.

Technology-mediated TBLT has also been shown to improve oral proficiency, pragmatic development, comprehension, and cultural understanding (Payne \& Whitney, 2002; Sykes, 2014; Yanguas, 2012). Learner engagement has also been shown to improve with technology-mediated TBLT (Lamb, 2004). Ziegler (2016) finds that computer-based 
tasks may help learners notice the forms and gaps and improve learner accuracy, especially when tasks are simple rather than complex. Additional studies by Pellettieri (2000) and Toyoda and Harrison (2002) also found this to be the case. Ziegler (2016) observes the importance of this with regards to Schmidt's (2001) noticing hypothesis, which emphasizes the importance of learners being aware of, or "noticing," specific features of the target language, such as grammatical form. He considers "noticing" to be a necessary condition of L2 acquisition and makes a connection between learners' awareness of a target form and its intake. This is relevant to the current study, which aims to provide specialized and individualized learning to a very specific group of learners. Doughty and Long (2003) found that technology-mediated tasks provide more opportunities for noticing than face-to-face tasks, leading to increased opportunities for learning.

In terms of task complexity, previous research suggests that while complex tasks in face-to-face learning have been shown to be advantageous for L2 learning, this is not the case for language learning with technology (Baralt, 2013; Ziegler, 2016). Task complexity refers not to the language used within the task, but to the inherent or unchanging qualities of a task that make it more or less challenging than other tasks (Long, 2015). Robinson (2001) describes task complexity as being the result of the amount of learners' attention, memory, and reasoning skills imposed by the structure or design of tasks. In contrast with face-to-face learning, Ziegler (2016) found that simpler tasks were found to lead to improved accuracy and fluency. Lai and Li (2011) also discuss task complexity with regards to CALL. They suggest that the reason simple rather than complex tasks appear to be more effective with CALL is due to the technology 
itself. They propose that the use of CALL media innately make online tasks more complex compared to face-to-face tasks, as learners are required to make use of their digital literacy skills in addition to their linguistic skills to interact with the task. They advise researchers to keep this in mind when applying a technology-mediated TBLT framework. In terms of simplifying tasks for CALL, Ziegler (2016) suggests that the traditional task cycle stages (consisting of a pre-task, task, and post-task) be disregarded, and the focus instead be on the task as a whole and how the implementation of the task addresses the needs of the learners and provides opportunities for learning.

With the understanding that the group of learners participating in this investigation has needs that are not currently being met, this study attempts to explore how these needs can be fulfilled through the development, implementation, and testing of an online module as part of a blended curriculum. Current research speaks to the advantages of the use of technology-mediated TBLT in blended learning contexts. Furthermore, Copaert (2004) emphasizes the importance of considering the context of the learner and the learner's needs prior to determining the technology to be used. Using the established needs (i.e., outside-the-classroom, flexible workplace language learning) and abilities (i.e., strong digital literacies), this approach seeks to gain both learner and teacher perspectives and insight on the module developed in order to explore whether the module and adopted approach (i.e., the use of MALL with a TBLT framework) are appropriately offering and delivering services that provide support to this group of learners. Because the development of the module(s) is intended to provide the volunteer teachers with additional support and guidance for their sessions, the teachers are considered and included in this study in addition to the learners. 


\subsubsection{Needs Analysis and technology-mediated TBLT}

Like the development of tasks, the use of needs analysis also becomes modified with the addition of technology. The use of needs analysis as part of the development of a technology-mediated, task-based curriculum has mainly been explored by GonzálezLloret (2014). González-Lloret builds upon Long's (2005) explanation of needs analysis, suggesting that researchers and practitioners expand their needs analysis to not only learners' linguistic needs but also their technological needs. Like Long, she stresses the use of needs analysis as the first step in developing a task-based CALL module. To do so, González-Lloret recommends assessing the technology itself prior to implementing it in the L2 classroom. This kind of needs analysis explores the appropriateness and suitability of the technology for the curriculum. This is an analysis of technology capabilities and affordances that considers what training and experience learners and teachers need to have in order to use the chosen tools successfully, including both their linguistic and digital literacy skills (González-Lloret, 2014).

\subsection{Blended learning}

While this study is focused on the development of an online module, this module, and the larger project, are situated in a blended learning context. This thesis uses the term blended learning to refer to the adopted pedagogical approach, however, this approach may also be referred to as a "flipped classroom". The flipped classroom is a subset of blended learning that provides learners currently engaged in face-to-face classroom learning with outside the classroom online learning materials, thereby freeing classroom time to complete other tasks (Abeysekera \& Dawson (2014). More generally, blended 
learning refers to a learning environment that combines both in the classroom and online learning (Grgurovic, 2011). It is an approach that is not unique to the field of second language acquisition and is considered to be one of the most significant recent advances in education (Thorne, 2003). Its use in language teaching is directly connected to CALL, with blended learning approaches being used increasingly, as CALL becomes more popular (Neumeier, 2005).

Neumeier (2005) considers blended learning to be somewhat complex. In order for blended learning to be successful, teachers must be able to provide learners with quality materials that are provided in an appropriate structure, particularly the online materials. This underscores the importance of developing materials that are grounded in the research and pedagogy (Ziegler, 2016). He states that the most important aspect to consider is the needs and abilities of the learners - something that is at the forefront of this study. This includes establishing the learners' linguistic needs as well as their digital literacy skills (i.e., their ability to use technology), alluding to the needs analysis described by González-Lloret (2014). In order for this to be achieved, Neumeier suggests that online materials be developed using a theory-based framework, such as the one proposed by Chapelle (2001) for implementing CALL. These criteria include considering the practicality, potential for learning, authenticity, and learner fit for the use of a specific type of CALL. This is important to keep in mind for the current study, which develops CALL as part of a blended curriculum.

Student perceptions of blended learning have been found to influence student use and engagement with CALL (Hong \& Samimy, 2010; Miyazoe \& Anderson, 2009). Miyazoe and Anderson (2009) developed a blended curriculum for students taking an 
English course at a university in Japan; following the completion of the course, they interviewed students to obtain feedback regarding the adopted blended approach, with emphasis on the CALL component. Students claimed to like the use of outside-theclassroom activities (such as writing blogs) in addition to face-to-face learning and described this method as both enjoyable and useful. Hong and Samimy (2010) found that student and teacher perceptions of blended learning influenced their attitudes towards the use of CALL. A positive perception of blended learning resulted in learners' increased interest in using CALL. Hong and Samimy suggest that this may connect to the fact that learners are receiving positive support from their teachers and therefore feel motivated and encouraged to engage in online learning.

Interestingly, Chen (2013) found that while one of the advantages of MALL is the ability to learn outside the classroom, the effectiveness of MALL is enhanced when it is combined with face-to-face learning, supporting the blended curriculum approach taken in this study. Egbert and Yang (2004) also found this to be the case. They observed that while the use of technology outside the classroom was effective in improving learners' language skills, it was important that learners also interact and engage socially with others (optimally, teachers or peers) in the target language, as this provides learners with more opportunities to use the language creatively.

While the module developed in this study is being done as part of an overall blended approach, the focus of the study is on the outside-the-classroom (online) learning with a module implemented using a MALL approach. An understanding of the benefits of a blended approach is important to keep in mind throughout the development of the module because of the context of the module in the overall blended approach. 


\subsection{Summary}

To summarize, this literature review has shown different aspects of research suited to the context of the study that have contributed to the development of the module. The context of the study indicates a need for outside the classroom learning, which is afforded through the use of CALL. Within the field of CALL, the portability and accessibility of MALL makes it best suited to the needs of the learners, who require flexible learning. While a MALL platform acts as the host for the module, a pedagogical approach must be also considered when designing and developing said materials. An exploration of TBLT demonstrates the advantages of applying an approach founded in meaningful, authentic, goal-oriented learning. The connection of MALL and TBLT is apparent through an exploration of technology-mediated TBLT, which combines the pedagogy of TBLT with the capabilities of CALL/MALL. The benefits of TBLT are maintained in this approach, but the technology is also considered. The advantages of using technology to host tasks become apparent along with the differences in implementing TBLT with technology compared to face-to-face learning. This is important as it ensures that tasks will be developed in a manner that capitalizes on the advantages of the technology while still being suited to the linguistic needs and abilities of the learners. This comes together as part of a blended approach to learning: learners continue to receive the weekly three hours of face-to-face learning in addition to the online learning. This sets up the context in which the module will be developed, and points to the advantages of providing learners with a combination of face-to-face and online learning. 
Bearing in mind the literature and the unique context for this study, the following research questions will be addressed:

1. What are the linguistic and technological needs of learners engaged in occupationspecific language training?

2. Can these needs be effectively incorporated into a technology-mediated TBLTbased module?

3. What is the perceived effectiveness of the module by teachers and learners in the occupation-specific language training program? 


\section{Chapter 3: Methodology}

\subsection{Overview}

This chapter explores the methodological approach taken to address the research questions and study goals. A three-tiered approach was taken here. This approach included (1) identification of the needs that this group of learners brought to the task of L2 learning through needs analysis, (2) designing the module using a technologymediated TBLT framework, and (3) testing the completed module and conducting interviews to receive feedback on its perceived effectiveness by learners and their volunteer teachers. This approach was followed in order to help tailor the module to the learners' goals and needs. Furthermore, this three-tiered approach guided the entire sequence of the design, with the previous tiers directly feeding into the subsequent ones. These tiers also address the three research questions explored in this study.

First, a needs analysis was conducted to determine the module's linguistic content and to assist with selecting an appropriate online platform to host said content. The environmental scan explores existing workplace language materials to determine what language learners need as part of occupation-specific language training. It also explored what online platform would be best suited to the needs of the learners through a "technology needs analysis" (González-Lloret, 2014). The overall design of the module was then done using the outcome of the needs analysis (i.e., using the linguistic themes revealed to be relevant to this group of learners during needs analysis) and applying a technology-meditated TBLT structure to materials hosted on the module platform. The remaining step of testing the module's effectiveness allowed for insight into learner and 
teacher perceptions of the module and helped determine the usefulness of the module contents to addressing the needs of this group of participants.

\subsection{Participants}

A total of eight participants were involved in this study. They all were associated with the employment support program and were recruited by the program facilitator. Participants were classified as language learners (newcomers needing workplace language support, $n=4$ ) and volunteer teachers (volunteers who provide workplace language support, $n=4)$. All participants had different experiences and backgrounds, which are discussed in detail below.

\subsubsection{Language learner participants}

Participants in the language learner group were all enrolled in the employment support program. All four participants had been employed through this program and, at the time of this study, were working in the customer service sector at various grocery stores. Three of the four participants were receiving ongoing weekly individualized workplace language training from an assigned volunteer teacher. However, one participant was not receiving any language training from the employment support program but had received some English language training from a volunteer teacher in the past.

All four participants in this group spoke Arabic as their first language and were all refugees (one from Syria and three from Iraq) who, at the time of the piloting and interviews, had been in Canada for less than a year. Learners had been assessed using the 
Canadian Language Benchmarks (CLB), which is a framework used to assess newcomers to Canada's English proficiency across the four skills of reading, writing, listening, and speaking. Learners are given a CLB level from 1 (beginner) to 12 (advanced), and this level is used to place newcomers in the appropriate ESL class. Each level of the CLB dictates the expected language abilities of the learner, acting as a guide in determining what linguistic skills should be taught to a given group of learners. In this study, language learner participants were considered to have a CLB level between 3 and 5 (i.e., highbeginner, low-intermediate English proficiency), with two learners having tested at level 3, one at level 4, and one at level 5. The CLB assigned to the learners had been determined through assessment done as part of their participation in the workplace support program. Being at the high-beginner, low-intermediate level of proficiency, the learners are expected to understand key words and formulaic phrases (i.e., "How are you? "), to follow speech at a normal rate in non-demanding situations, and to produce simple sentences about everyday wants and needs. Learners at this level may require assistance, including repetition and paraphrasing, and may depend on the presence of contextual cues in the input (Centre for Canadian Language Benchmarks, 2012).

The learners participating in the employment support program are newcomers working in customer service, and as such, need language training focused on the specific language used in the customer service sector (as mentioned previously, customer service refers to employment in which an individual regularly interacts face-to-face with customers in positions such as a cashier or handing out food samples at a grocery store). These individuals often have varying schedules due to the shift nature of their work and also have additional personal and family commitments. One learner had completed some 
face-to-face language courses but was forced to withdraw from these classes due to work commitments, exemplifying the challenges that learners face regarding attending face-toface language classes. Therefore, these learners face the challenges described by Shaffir and Satzewich (2010) and are not easily able to attend regularly scheduled face-to-face classes.

An intake questionnaire given to individuals as they enter the program that asks what devices learners use and prefer to use for communicating revealed that all learners had mobile devices (as opposed to computers) and that they preferred to communicate using these devices. Therefore, the application of CALL, or more specifically MALL, was well suited to the context of this study. MALL is flexible, portable, and convenient, which nicely aligns with the fact that the target group of learners has varying schedules and is not able to attend language classes. The use of MALL also spoke to the abilities (i.e., the digital literacy skills) of the learners. Challenges can arise when implementing CALL if learner digital literacy skills are not considered (Neumeier, 2005). Digital literacy skills with mobile devices was reported to be high, and program organizers reported that communication over mobile chat apps was more easily maintained than that of other media such as email.

\subsubsection{Volunteer teacher participants}

The teacher participants were all volunteers with the employment support program. As part of their volunteer agreement, each volunteer teacher was paired with a language learner and was expected to meet with the learner weekly for three hours over a three-month period. The background of each volunteer participant varied. Three of the 
volunteer teachers were native speakers of English, while one reported Turkish as his mother tongue, with English being an L2. Teaching and employment experience also varied between the volunteer teachers: one was fully certified by TESL Canada as an English as a second language teacher, two had previously taught English in foreign language contexts, and the remaining volunteer teacher had no previous teaching experience (second language or otherwise) prior to volunteering with the employment support program. The volunteer who had taught English overseas had experience using digital platforms for teaching and had previous experience using this type of platform as a second language learner. The teachers providing weekly language training sessions are volunteers who have various levels of experience, and who, like the learners, also have additional commitments related to work or family. One of the volunteer teachers was a student, while the remaining three teachers had full-time jobs. Unlike the learner participants, these jobs were not in customer service or shiftwork. However, because of their work hours, the volunteer teachers reported that they were often only able to meet learners in the evening or on weekends.

\subsection{Needs analysis}

As mentioned previously, needs analysis is a pedagogical tool that assesses the needs of learners in order for a curriculum to be developed that is suited to their given needs (Benesch, 1996). Needs analysis typically involves exploring the linguistic needs of the learners as well as their linguistic goals and plays a central role in task-based learning (González-Lloret, 2014; Long, 2005). However, an additional component to needs analysis must be considered when using CALL. González-Lloret (2014) discusses 
the importance of completing a needs analysis that analyzes both the linguistic and technological needs of the learners when using technology for language learning. Hence, to develop a module that is in line with the linguistic and technological needs of the participating L2 learners, two types of needs analyses were conducted. The first needs analysis focused on the language and involved (1) a scan of published instructional materials for the workplace and (2) observations in the workplace. The second analysis emphasized the role of technology and included an examination of the currently available online learning platforms with the goal of choosing the one that best suited the target context.

\subsubsection{Linguistic needs analysis}

An environmental scan was conducted as part of the linguistic needs analysis and consisted of two main components: the scanning of existing resources (i.e., textbooks) that contain workplace language as well as conducting workplace observations. This was done to collect linguistic data, to identify language that is used within the workplace most often, and to ensure that the language to be used within the module would be authentic. The use of authentic materials can help connect learning materials to the real world and provide more meaningful exposure to the language (Tomlinson, 2012). Authentic language is a key factor of task-based language learning (Willis \& Willis, 2007), and it was therefore important that the language used within the module be accurately reflective of language used in customer service. Additionally, the environmental scan was done to aid in the selecting of the topic for the module. The scan allowed for an exploration of linguistic themes present in customer service. The most recurrent type of language was 
selected to be the theme of the module since it was the first, pilot module in a ten-module program.

The first component of the environmental scan involved scanning existing workplace language resources to identify and extract language used in the workplace. This was done by examining a total of 14 workplace language textbooks and online workplace language resources. These 14 resources are freely and readily available resources in Canada and are likely to be used by those wanting workplace language content, including the volunteer teachers with limited or no L2 teaching background. These online resources consisted of resources created by various Canadian colleges and the Canadian government, with the intention of providing workplace language support to newcomers. It should be noted that not all of these resources focused on the selected domain of customer service, but all were focused on workplace language. A complete list of materials and resources scanned can be seen in Table 1 . The resources in this table include both the physical textbooks (e.g., The Interface Canada Series [2007] and the online resources from Norquest College [2010; 2018] and Bow Valley College [2018]). All resources were chosen because they are Canadian and have been published with support from the Canadian government. The Interface Canada Series (Canada School of Public Service, 2007), for example, has been directly published by the Government of Canada and is designed to provide workplace language support with a focus on listening and speaking skills. While the early books in the series are designed for lowerintermediate level learners, the later volumes were written for upper-intermediate learners (Government of Canada, 2018). The online resources were published in partnership with the Alberta Open Education Resources and provide support for learners with a Canadian 
Language Benchmark (CLB) of 5 to 6 . They are designed using a four-skills approach (reading, writing, listening, and speaking) and include thematic units focused on topics relevant to the needs of Canadian newcomers (Bow Valley College, 2015).

Table 1.

Environmental scan resources

\begin{tabular}{|l|l|}
\hline Resource & Publisher \\
\hline $\begin{array}{l}\text { Here to help: Workplace communication skills } \\
\text { for food services }\end{array}$ & Bow Valley College (2018) \\
\hline $\begin{array}{l}\text { In the workplace: An intermediate integrated } \\
\text { skills textbook }\end{array}$ & Bow Valley College (2018) \\
\hline Interface Canada 1 & $\begin{array}{l}\text { Canada School of Public Service } \\
(2007)\end{array}$ \\
\hline Interface Canada 2 & $\begin{array}{l}\text { Canada School of Public Service } \\
(2007)\end{array}$ \\
\hline Interface Canada 3 & $\begin{array}{l}\text { Canada School of Public Service } \\
(2007)\end{array}$ \\
\hline Interface Canada 4 & $\begin{array}{l}\text { Canada School of Public Service } \\
(2007)\end{array}$ \\
\hline Interface Canada 5 & $\begin{array}{l}\text { Canada School of Public Service } \\
(2007)\end{array}$ \\
\hline Interface Canada 6 & $\begin{array}{l}\text { Canada School of Public Service } \\
(2007)\end{array}$ \\
\hline Interface Canada 7 & $\begin{array}{l}\text { Canada School of Public Service } \\
(2007)\end{array}$ \\
\hline Interface Canada 8 & $\begin{array}{l}\text { Canada School of Public Service } \\
(2007)\end{array}$ \\
\hline $\begin{array}{l}\text { Common ground: Guide to English in the } \\
\text { workplace (Phase 2) }\end{array}$ & Norquest College (2010) \\
\hline $\begin{array}{l}\text { Common ground: Guide to English in the } \\
\text { workplace (Phase 3) }\end{array}$ & Norquest College (2010) \\
\hline LINC works curriculum & Norquest College (2018) \\
\hline $\begin{array}{l}\text { Online workplace integration language } \\
\text { resources }\end{array}$ & Norquest College (2018) \\
\hline & \\
\hline
\end{tabular}

The second component of the environmental scan involved observing employees working in customer service in the workplace. Observing the environment allows for a more realistic picture as to what is happening in the given domain (Long, 2005). A total of three workplace observations (each lasting a total of three hours) were conducted, 
during which a total of five customer service employees were observed at their place of work. Four of the employees observed were L2 learners participating in the employment support program. Three of these individuals were employed as cashiers in a bakery, while one was employed to hand out food samples at a grocery store. The fifth employee observed was a native English speaker and was also responsible for handing out food samples. This allowed for a more direct comparison of the similarities and differences used by a non-native and native speaker with the exact same job. For example, the nonnative speaker didn't initiate small talk with the customers and waited for them initiate conversation, while the native speaker initiated with longer phrases and engaged in more small talk with all customers. The non-native speaker would greet customers repeatedly by saying "Hi!", only saying more if then approached by customer, while the native speaker would often greet customers with a few different phrases, including "Hi, how are you?" or "Hi, would you like to try ___ ?". While these differences were interesting to observe, and may be present due to these individuals having different language proficiencies, other factors may also have played a role, such as personality. During these observations, field notes on the language used were taken. These field notes can be seen in Appendix B.

\subsubsection{Technology needs analysis}

As part of the technology needs analysis, various online platforms were explored in order to find one best suited to hosting the module. Chapelle (2001) suggests criteria for evaluating a CALL platform. She encourages considering the specific learning situation, the pedagogical approach, and the language learning potential of the software. 
These criteria were further considered by Hubbard (2006), who adapted them to include considering learner fit as well as the practicality and positive impact of the software or platform. With regards to conducting a needs analysis as part of technology-mediated TBLT, González-Lloret (2014) advises asking "what do the learners need to do, in what context is it going to happen, [and] will it be mediated by any tools?" (p. 37). She observes that not all technical tools are equal, and that a needs analysis of the tool is crucial to discovering the most effective tool for the given context. She advocates for the use of needs analysis as part of the technology selection process. In this study, the learners need flexible online learning that allows for them to learn language required to work in customer service. The chosen platform needed to address the needs of the learners (i.e., to be usable on a mobile device) and to be able to host materials in a manner that followed the proposed TBLT framework.

From information gathered from the employment support program, it was determined that the group of learners prefers to use mobile devices, and existing research supports the use of a mobile platform due to the adaptability of use (Kukulska-Hulme, 2007). The portable and accessible nature of mobile learning was also considered to be well suited to the needs of the learners. With this in mind, the scope of platforms and software being considered as a host for the module excluded those not accessible via a mobile device. With regards to the pedagogical approach, a technology-mediated TBLT approach was desired, which meant that the platform needed to be able to host materials in a manner that allowed for negotiation of meaning and that were goal-oriented, authentic, and realworld based (Ziegler, 2016). Therefore, a platform that is available as a mobile app and is highly customizable was identified as necessary to host the module. 


\subsection{Designing the module}

The real-world based, authentic, and goals-oriented characteristics of TBLT were factors in the decision to follow a task-based framework. Various steps were taken to ensure that the designed module spoke to the TBLT goals in general while adhering to the capabilities of the particular technology. These capabilities include (1) activation of cognitive, behavioural, attitudinal, and social mechanisms, (2) improvement in oral proficiency, pragmatic development, comprehension, and cultural understanding, and (3) learner engagement and individualized learning (Yanguas, 2012). With these in mind, the module aimed to incorporate tasks that allowed for contextualization, language practice, and prediction. The contextualization tasks allowed learners to use behavioural and social mechanisms in order to understand cultural behaviours in customer service, activating cognitive mechanisms. This directly connected with the language practice and production elements of the module, which relied on the activated cognitive mechanisms from the contextualization portion of the module. The language practice tasks built on this knowledge and allowed learners to gain linguistic input while completing tasks that developed comprehension, oral proficiency, and pragmatic awareness. Finally, the prediction portion of the module brought together the contextualization and language practice portions of the module. Learners were required to use the knowledge from these sections and apply it in a more demanding capacity, further activating cognitive mechanisms while opportunities for language production and comprehension were provided. Together, these components of the module were designed to encourage learner engagement and individualized learning. Learners maintained control throughout the 
module, and while the overall structure of the module tasks was designed to guide learners, learners were able to control how and when they interacted with the module.

\subsection{Piloting and testing the module}

Upon completion of the module, both the learners and their teachers were invited to pilot the tasks within the module and to share their thoughts in a one-on-one interview. The piloting and interview process will be discussed here.

\subsubsection{Piloting}

Participants were initially asked to pilot only the first (i.e., greetings) portion of the module and were given access to the module on a mobile device and asked to complete it. Participants were not given instruction on the use of the module in order to determine how intuitive the chosen online platform was to use. The locations in which the module was piloted varied based on the availability of the participants. One participant asked to be able to pilot the module at her place of work during her lunch break. The remaining participants requested that the module be piloted during one of their sessions with their volunteer teacher, citing limited availability. When the module was piloted during a session with a volunteer teacher, the module was piloted twice: once by the learner and once by volunteer teacher. There was no assistance provided by the volunteer teacher during learner piloting of the module and vice versa.

Following the development of the full greetings and requests module, participants were asked to pilot the updated module. Similar conditions were followed during the piloting of the module: location of the piloting varied and was done based on the 
availability of the participants. At both test times, participants were given unlimited time to complete the module.

\subsubsection{Conducting interviews}

Interviews were conducted with participants following piloting in order to obtain feedback on the usability, design, and content of the module. According to Dörnyei (2007), a "good" qualitative interview has two key features: “(a) it flows naturally, and (b) it is rich in detail" (p. 140). Interviews were single-session and were semi-structured in nature. By using a semi-structured approach, there was flexibility in the overall format of the interviews, allowing for open-ended discussion (Dörnyei, 2007). The use of interviews to obtain feedback regarding the use of CALL has also been suggested by González-Lloret (2014), who notes that interviews are an effective way to obtain feedback regarding the use of a given technology. Each interview was approximately 45 minutes long. Participants were asked questions regarding their thoughts and perceptions of the module ("What did you like about the module?", "What would you change about the module?"), including their opinions on the chosen online platform ("Was the software easy to use?"). A full list of questions used to guide the interview process can be seen in Appendix C. Participants were also invited to contribute and discuss any other elements of interest or observations that they had made during the piloting stage. Feedback obtained during these interviews was used to determine the participants' overall thoughts regarding the module, with their suggestions being integrated into the final version of the module. A discussion of the feedback received by participants-including positive 
feedback, suggestions for modification, and how the module was modified to reflect these suggestions-will be examined in the results and discussion chapter. 


\section{Chapter 4: Results and Discussion}

\subsection{Introduction}

The results to this study will be presented and discussed with regards to the three research questions asked: (1) what are the linguistic and technological needs of the learners, (2) can these needs be incorporated into a technology-mediated task-based module, and (3) what is the perceived effectiveness of the completed module by teachers and learners? The first research question will be addressed through the results of the needs analysis, the second through the overall design of the completed module, and the third by way of the feedback received through the piloting and interview process. A discussion of the results as to how they relate to the development of the module, and how they address the needs of the learners, will also be included.

\subsection{Research question 1: Linguistic and technological needs of learners}

\subsubsection{Needs analysis}

The results of the needs analysis speak directly to the first research question, which asks, what are the linguistic and technological needs of learners engaged in occupation-specific language training? The linguistic needs analysis provides insight into the language needs of the learners, while the technology needs analysis provides insight into the technological needs of the learners.

The discussion of needs analysis is broken down into (1) the more traditional linguistic needs analysis and (2) the technology needs analysis proposed by GonzálezLloret (2014). The outcome of the linguistic needs analysis allowed for the selection of a 
theme relevant to the linguistic needs of learners working in customer service, while the outcome of the technology needs analysis allowed for these needs to be addressed with an online module platform that allowed for the language identified in the environmental scan to be incorporated into the module effectively, while still addressing the needs of the learners (i.e., that it allow for flexible, outside-the-classroom learning, enabling learners to access the language training they need at any time and place).

\subsubsection{Linguistic needs analysis}

The scan of the textbooks and online resources along with the in-person observations provided evidence that greetings and requests are among the most used types of language in everyday interactions within the customer service sector. Greetings were initially considered to be the most prevalent theme of the environmental scan. However, the use of this theme alone would not be enough to sustain the module for the desired length (45 minutes to an hour). Therefore, the next prevalent theme of requests was also considered, and both themes were selected for the module.

However, because "requests" is very broad category, it needed to be narrowed for the scope of the module. To this end, it was decided that requests would be limited to what Long (1983) refers to as requests to negotiate meaning. These requests can be used to help learners during communication breakdowns (Cook, 2015) and allow them to assess whether or not they have been successful at communicating with native/proficient speakers (Long, 1983). There are three different types of requests within this category. These are referred to by Long as requests for clarification ( "What do you mean?"), requests for confirmation ("You want this one?"), and comprehension checks, also 
known as repetition ("You want ?"). These requests allow for more information and comprehensible input to be obtained and can help prevent communication breakdowns (Cook, 2015). Furthermore, these types are meaning-focused rather than form-focused, aligning with the principles of TBLT. Long and Porter (1985) assert that the importance of requests to negotiate meaning is the focus on what a communication partner is saying and not on how they are saying it. Clarification requests as well as confirmation and comprehension checks provide learners with the opportunity to repair communication breakdowns in the same manner as native speakers and provide opportunities for learners to verify meaning and express uncertainty (Long \& Porter, 1985).

The inclusion of requests to negotiate meaning also aligns nicely with the fact that the proficiency level of the target learners may have them seek assistance in the form of repetition, further explanation, or rewording in order to help them understand a native/highly proficient speaker of English (Centre for Canadian Language Benchmarks, 2012). Long and Porter (1985) observed that intermediate level learners were more likely to engage in requests to negotiate meaning than advanced learners, suggesting that such requests are appropriate for the learners in this study who can be considered lowintermediate learners.

Within the textbooks and online resources, greetings and what were referred to as “clarifying requests” (Bow Valley College, 2018; Norquest College, 2010, 2018) were often grouped together in the same chapter. Many of the online resources, including the Bow Valley (2018) and Norquest $(2010,2018)$ materials, introduced greetings and clarifying requests relatively early (usually within the first two chapters) and then revisited these themes throughout, especially greetings. When grouped together, these 
themes often fell under the heading of "politeness", and they were often introduced from a pragmatic perspective (i.e., what is appropriate in Canadian culture, what is considered polite, and how/when this language is used). The Interface Canada series also introduced greetings in its early chapters, but it did not group them with any type of request for negotiation. These types of requests were introduced later and were referred to as "polite requests" (Canada School of Public Service, 2007).

Interestingly, the significance of learning these themes (greetings and requests) has also been identified in research by Bartel (2018), who discusses the importance of soft skills in the workplace. She identifies linguistic soft skills that should be taught to learners in order to facilitate success (i.e., maintaining or advancing in employment) in the workplace. Two of the soft skills Bartel discusses include making small talk and asking questions. In Bartel's research, the definition of small talk overlaps with the elements of greetings found in the environmental scan. For example, a recurring greeting found in the textbooks and online resources was "Hi, how are you?". The "How are you? " portion of this phrase is also considered to be small talk. The "asking questions" soft skill referred to by Bartel includes the requests identified in the environmental scan (clarification, confirmation, and comprehension checks). While the environmental scan and needs analysis were identified using the environmental scan, the fact that these are themes discussed by research can further guide the development of tasks within the module. For example, Bartel notes that learners likely are already familiar with question structure and syntax and that focus should instead be on the appropriateness and respectfulness of questions. She suggests questions be taught through awareness-raising (i.e., by drawing learner attention to requests). 


\subsubsection{Technology needs analysis}

As mentioned previously, learners require a platform that is flexible, accessible, and portable, calling for a platform hosted using MALL, as it offers learners these affordances. Recall also that the platform will need to host materials in a manner that adheres to the principles of TBLT. Learner needs and consideration of the desired technology-mediated TBLT framework were the driving factors behind the needs analysis and in the selection of the platform.

Prior to establishing the final platform to host the module, other platforms were considered. When beginning to work with the employment support organization, a specific platform was initially considered to be used for this project. This initial software is discussed only briefly, due to it no longer being part of this project. This software was hosted only on computers, not mobile devices, and was only accessible on certain types of computers and had to be installed on each computer prior to its use, limiting its accessibility. It had a set structure that made it difficult to follow the criteria for developing tasks. Further exploration of the needs of the learners and the pedagogical approach indicated that this software was not well suited to the needs of the learners. It was not easily available, and it did not allow for the technology-mediated TBLT framework to be implemented. While this software was ultimately not used with to host the module, it is mentioned briefly here in order to demonstrate the importance of selecting software that addressed the needs of the learners. This emphasized the importance of conducting González-Lloret’s (2014) needs analysis of the technology with emphasis on the question, does the technology address the needs of the learners? The use 
of needs analysis prior to using the software mitigated challenges that would have arose (such as developing pedagogically sound materials and distributing the software to the learners) had a software such as this been selected to host the module.

It was important to select a platform that was easy to use and available on mobile devices. Levy and Stockwell (2006) emphasize the importance of choosing a platform that is not only suited to the language needs of the learners, but is also capable of hosting materials that will allow learners to achieve their language goals. Bearing this in mind, and considering the needs of the learners, the e-learning software Moodle was selected as it fulfilled these criteria. Moodle is an open-source, freely available software that allows for learning on both computers and mobile devices (Costello, 2014). It is highly customizable, which was beneficial from a pedagogical perspective as this meant that it was possible to incorporate materials into the module that followed the desired pedagogical framework (i.e., TBLT). Furthermore, Moodle is designed to be used for blended learning (i.e., to support rather than replace face-to-face learning) and has previously been praised for being user friendly (Horvat, Dobrota, Krsmanovic, \& Cudanov, 2012). It has also been used as a platform for L2 learning with success. Brandl (2005) praised Moodle for its ability to hold a wide variety of resources for language learning, while Jingwei (2013) found that the customizability and flexibility of Moodle in developing materials was an asset and concluded that its use as part of a blended curriculum to be effective.

With regards to using Moodle on a mobile device, an app can be downloaded and installed directly onto a mobile device, and within this app, the module can be downloaded. During the piloting of the module, participants were able to use this mobile 
Moodle app to test the module. Downloading the module within the app means that learners can use their mobile device for learning without being constrained to environments where there is no internet access. Moodle is what is known as a course management system, meaning it can hold a substantial amount of materials. Looking at the larger ten module project, this was significant, as all modules can easily be hosted within one Moodle course, again making access easy for learners. Learners and volunteer teachers would be provided with log-in information, giving them access to a "course" where they would find a "catalogue" of the ten modules. They would be able to choose a module (or multiple modules) from a list, download it onto their mobile device, and use it any time and place, providing them with access to the language support they need, when they need it.

The use of needs analysis speaks directly to the first research question, which asks about the linguistic and technological needs of the learner. The linguistic needs analysis results indicate that greetings and requests are prevalent in customer service, suggesting that learners will need to be familiar with this type of language and its use to be successful in the workplace. This reinforces the selection of this theme for the first module. The technology needs analysis results indicate that a customizable mobile platform such as Moodle is best suited to addressing the technological needs of the learners. This MALL platform is portable and accessible, which aligns with the fact that learners need a flexible platform designed for outside-the-classroom learning. In summation, Moodle addresses the learner needs and enables the use of a technologymediated TBLT framework to host the materials. 


\subsection{Research question 2: Incorporating learner needs into a technology- mediated module}

\subsubsection{Designing the module}

The second research question asks, can learner needs (identified by the needs analysis) be incorporated into a technology mediated module? This question is investigated through the design of the module itself.

The design of the module incorporates the language identified in the environmental scan, focuses on greetings and requests for negotiation of meaning, and develops tasks that allow for learners to interact with this target language in a manner that is authentic, real-world based, meaning-focused, and in line with the mobile platform chosen through the needs analysis. Based on the analysis of the affordances associated with the technology-mediated TBLT framework, it was deemed necessary for the module to include tasks that allowed for contextualization, language practice, and prediction opportunities. The module begins with greetings as the theme, with the theme changing to requests for the second portion of the module. Both themes provide learners with contextualization, language practice, and prediction tasks in this order. An overview of the flow and order of task types within the module can be seen in Table 2. However, the task for each of these components is not the same across both parts of the module. A more detailed explanation of the module contents follows. 
Table 2 .

Module structure and task order

\section{Part 1: Greetings}

1. Contextualization Questions

2. Language Practice

3. Prediction Tasks

\section{Part 2: Requests}

1. Contextualization through Narrative

2. Language Practice

3. Scenarios (Language Practice/Prediction Tasks)

\subsubsection{Part 1 of the module: Greetings}

Since contextualization has been considered to be a strength of TBLT (Beglar \& Hunt, 2002), the inclusion of a contextualizing component was done to allow for scaffolding and schema building (Gonulal \& Loewen, 2018) as well as to help learners make use of this knowledge to complete the remaining portions of the module. To contextualize the language of the module (for both the greetings and requests portions), learners were first asked to watch a video of an interaction between a customer service representative and a customer. Following the video, they answered a series of multiplechoice questions regarding the context and interaction depicted in the video (e.g., "Who are the people in the video?"). Figure 1 provides an example from the greetings portion of the video, where the learners can see a customer service representative greet two different customers. This video models these interactions for the learners, allowing them to use cues within the video to determine the context, thereby activating cognitive mechanisms. The follow-up questions guide and help reinforce the context for the learners. 


\section{Watch the video and answer the questions.}

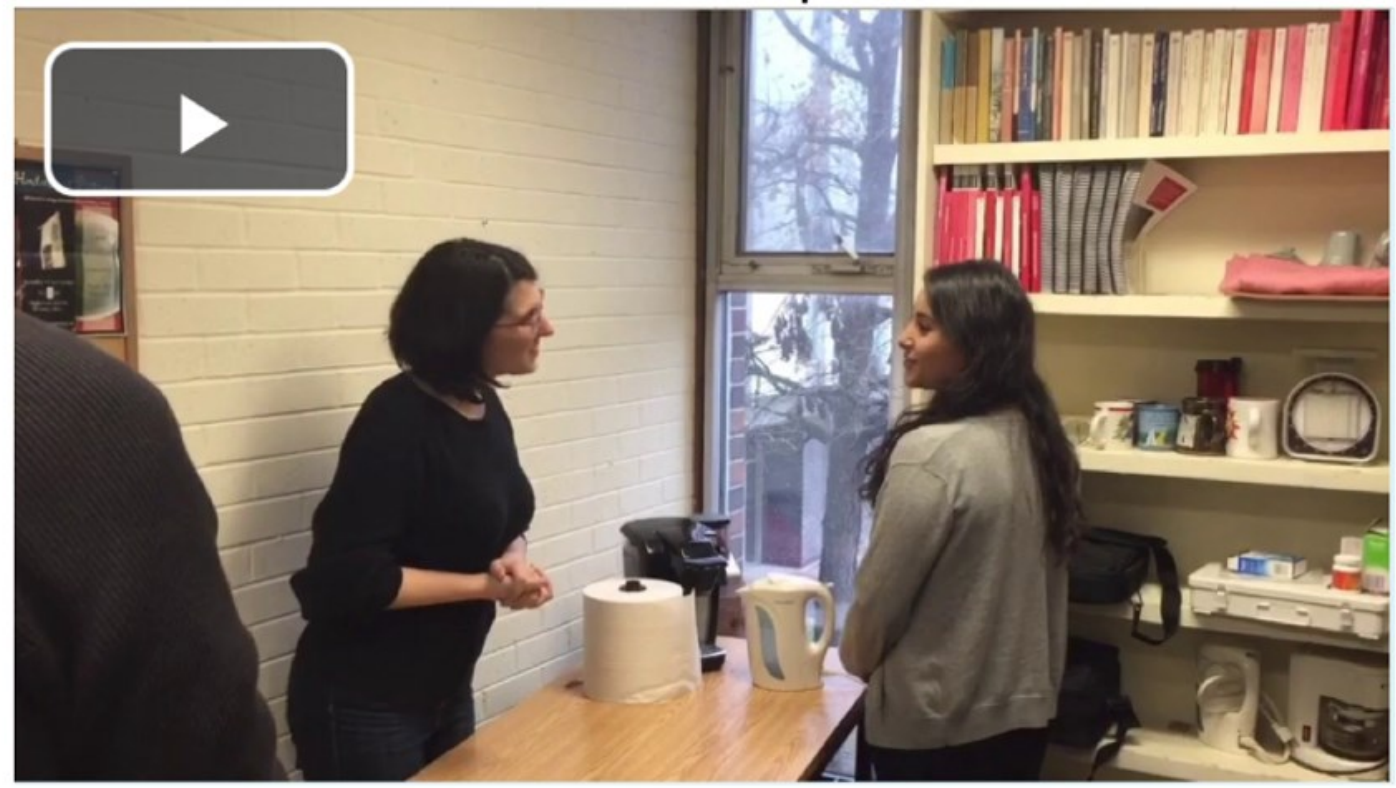

\section{Who are the people in the video?}

\section{a. Family \\ b. Friends \\ c. A customer service representative and customer}

Figure 1. Example of a greetings contextualization question

Following the contextualizing questions, the learners were then asked to watch the same video again, but this time, learner attention was drawn to the language used in the video. Specifically, the learner was asked to focus on the responses provided by the customer in the scenario to highlight the type of language typical in such interactions. As Figure 2 shows, learners are asked to type in a response to the "How does the customer service representative say hello?" question. 
Watch the video and answer the questions.

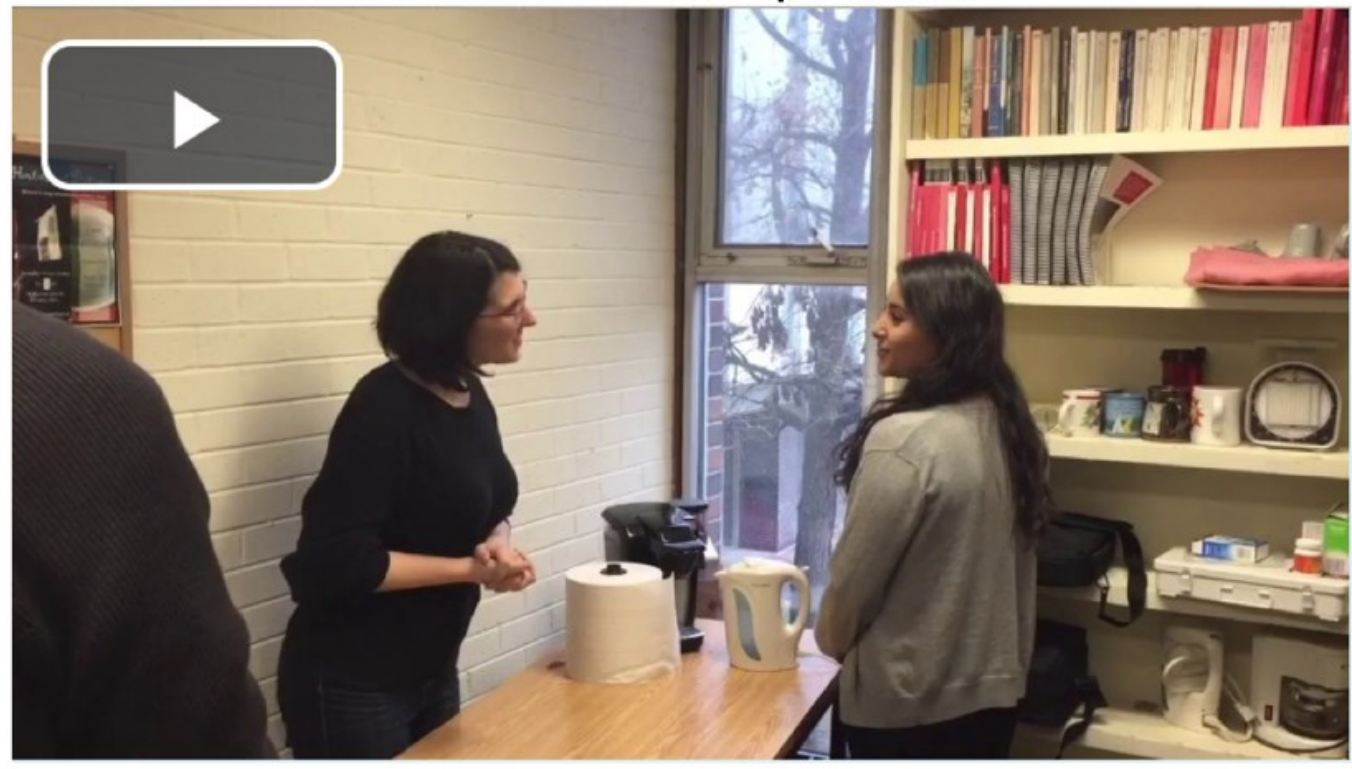

How does the customer service representative say hello?

Figure 2. Example of greetings language practice

Following this, learners would continue their language practice by watching additional videos of interactions between customer service representatives and customers, and matching each video to a short summary or description of the video contents. For example, a video in which a customer service representative says, "Thank you. Have a good night" to a customer could be matched with this description: "The customer service representative finishes helping a customer." An example of this type of task can be seen in Figure 3. 
Match the video to the correct description.

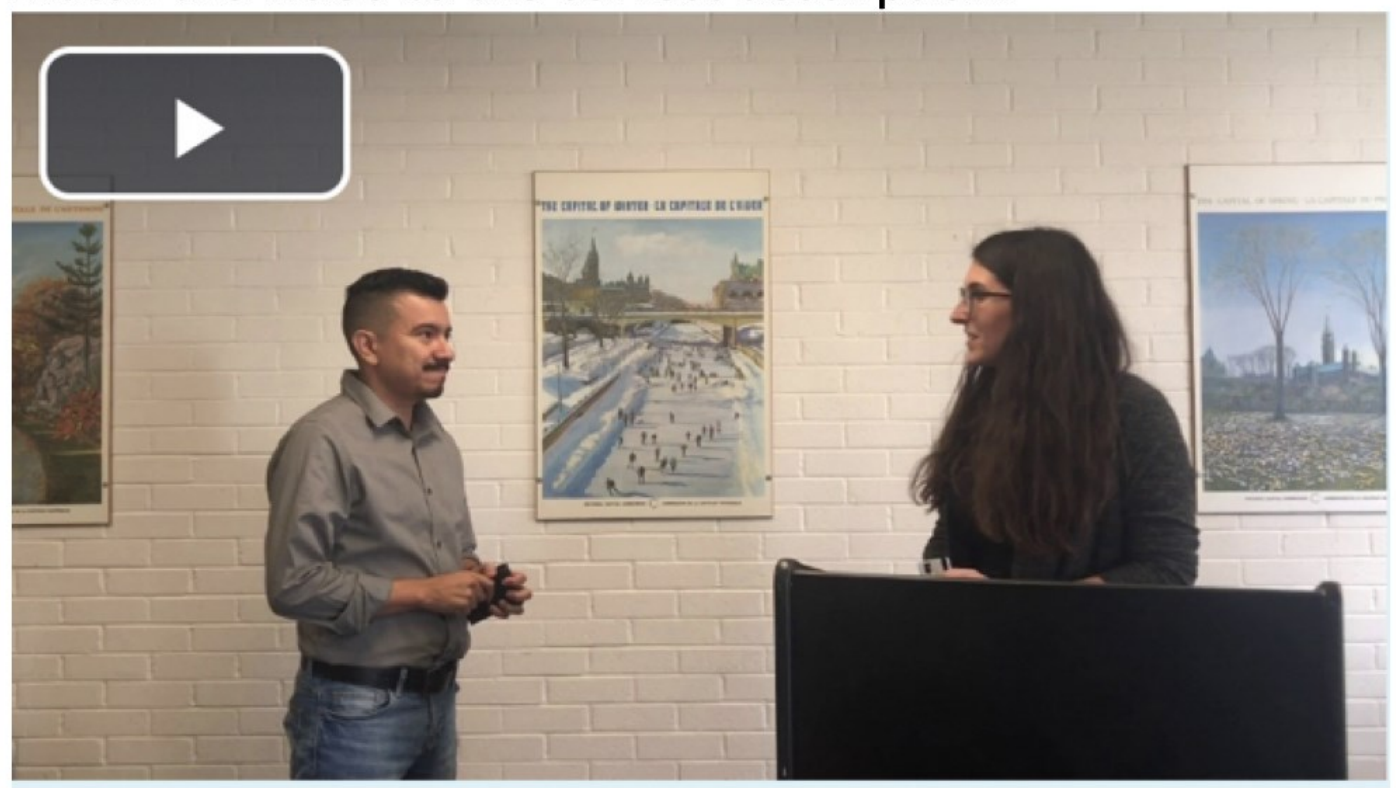

a. The customer service representative talks about the weather with a customer

b. The customer service representative finishes helping a customer

c. The customer service representative says hello to a customer

Figure 3. Greetings matching question

The next part of the module involves learners applying the language they had been exposed to up to that point. Two types of tasks were used for the prediction phase of the module. For the first task type, learners watched videos of incomplete interactions between a customer service representative and a customer, and were asked to predict what could happen next. For example, one of the videos includes an interaction between a customer service representative and a customer in which they are interrupted by another customer. After watching the video, the learner is asked, "What could the customer 
service representative say next?" and is invited to type in an answer in the provided space. It is important to note that in designing this task, we knew that multiple correct answers could be provided by the learner. This meant that extra consideration needed to be made with regards to the feedback that learners would receive upon submitting their answer. Specifically, in order to avoid prescribing one correct answer, learners were provided with an example of a possible response and were then advised to discuss their original answer with their teacher (Figure 4). In addition to avoiding prescribing only one answer, this consideration helped connect the online modules to the face-to-face sessions with the volunteer teachers as part of a blended curriculum. Volunteer teachers could review the learner's answers to the prediction tasks and use them to guide the face-to-face session. For example, if a learner provided an answer that was grammatically incorrect, the session could include focus on the correct grammatical form, or if the answer was pragmatically inappropriate, the session could discuss why this answer was not suitable for the situation. Even if the learner's answer was accurate, it could still be used to guide a discussion of other possible response options. 


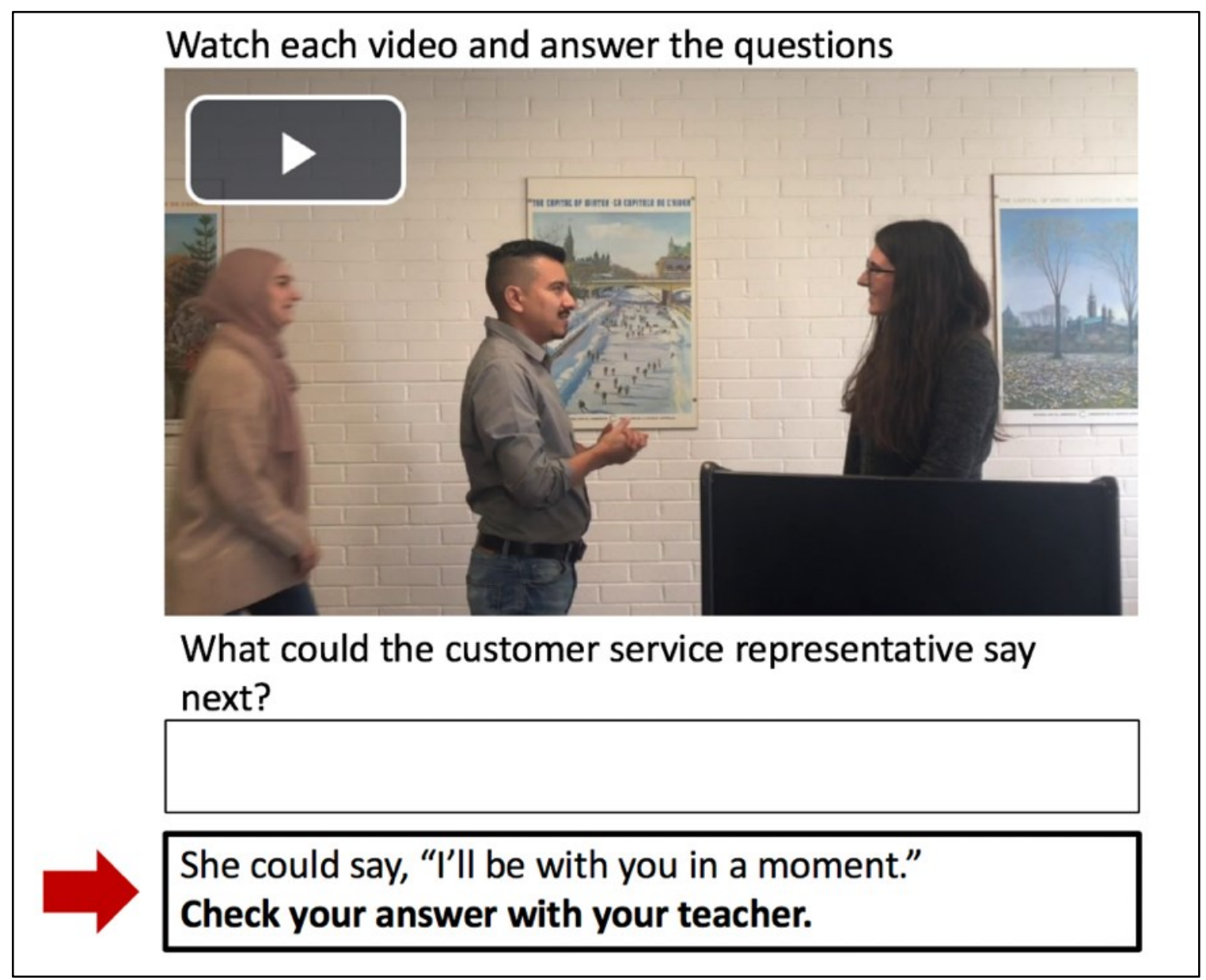

Figure 4. Greetings prediction task with feedback

\subsubsection{Part 2 of the module: Requests}

Like the greetings portion of the module, the requests portion begins by providing contextualization for the learner. However, rather than providing contextualization of the setting or environment, here contextualization is concerned with the shift in topic from greetings to requests. The contextualization also differs in that it does not require learners to watch videos and answer questions. Here, contextualization is done through the use of a narrative (Barkhuizen, 2008). This narrative was designed to act as a model of requests to negotiate meaning for learners and to reduce learner anxiety regarding not always 
being able to understand customers. The narrative follows a customer service representative who is an L2 English speaker, and who at times does not understand a customer. The narrative states what the customer service representative does when this occurs by introducing Long's (1983) requests for negotiation as strategies to prevent or mitigate communication breakdowns. An example of the narrative can be seen in Figure 5. The narrative is designed to provide context and input for learners, and learners are not asked questions regarding the narrative. This narrative also sets up a "character" who is referred to throughout the remainder of the module. This character (named Sarah) is designed to represent a customer service representative who has the same linguistic needs and faces challenges that the learners themselves may encounter working in customer service.

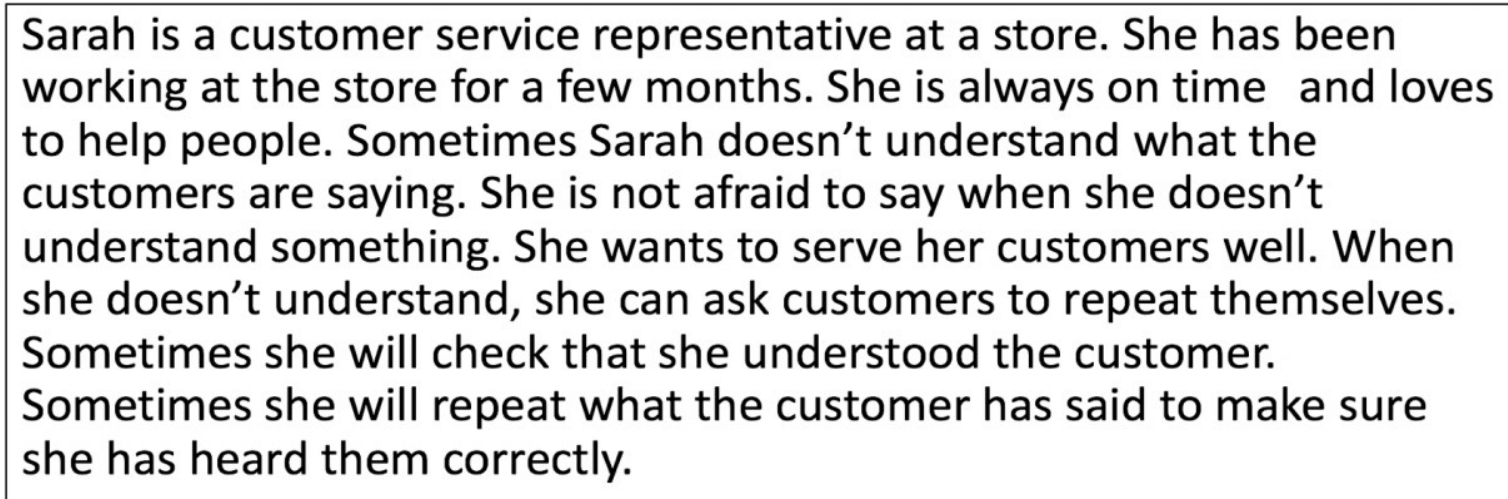

Figure 5. Requests narrative for contextualization

Following the contextualizing narrative, the module provides opportunities for language practice for the learners. This resembles the language practice tasks present in the greetings portion of the module. Learners are once again asked to watch videos of interactions between a customer service representative and a customer. However, unlike the language practice section of the greetings portion of the module that asks learners to 
watch one video that they were familiar with from the contextualization section of the greetings portion of the module, learners are asked to watch three different videos that are completely novel. This means that an increased cognitive demand is placed on the learners. This speaks to the complexity of the task, as the tasks are becoming more linguistically complex, requiring learners to use greater memory, attention, and reasoning skills (Robinson, 2001). The structure of the tasks is maintained, as this is shown to be advantageous with CALL (Lai \& Li, 2011; Ziegler, 2016). Learners remain familiar with the task structure but are not familiar with the video's (linguistic) content. The demands of the tasks increase throughout the module, with learners relying on their experiences with questions earlier in the module to complete the more challenging aspects of the new task (Gonulal \& Loewen, 2018).

A total of three videos were included for the language practice in the requests module. Three videos allowed for learners to view an interaction using a request to negotiate meaning (either comprehension check, confirmation, or clarification). The differences in these requests are not explicitly explained to the learners, but the videos expose learners to input that demonstrates the scope and use of these types of requests. An example of one of the language practice videos and the subsequent question can be seen in Figure 6. Learners are asked to watch the video of an interaction between the customer service representative and a customer, in which Sarah does not understand what the customer is asking. Sarah uses a clarification request ("Can you say that more slowly? "), gets more information from the customer, and is then able to understand what the customer wants. Following the completion of the video, learners are then asked about 
the language used in the video ("What did Sarah say when she didn't understand the customer?"), drawing their attention to the clarification request.

\section{Watch how Sarah talks to the customer in the video and answer the questions.}
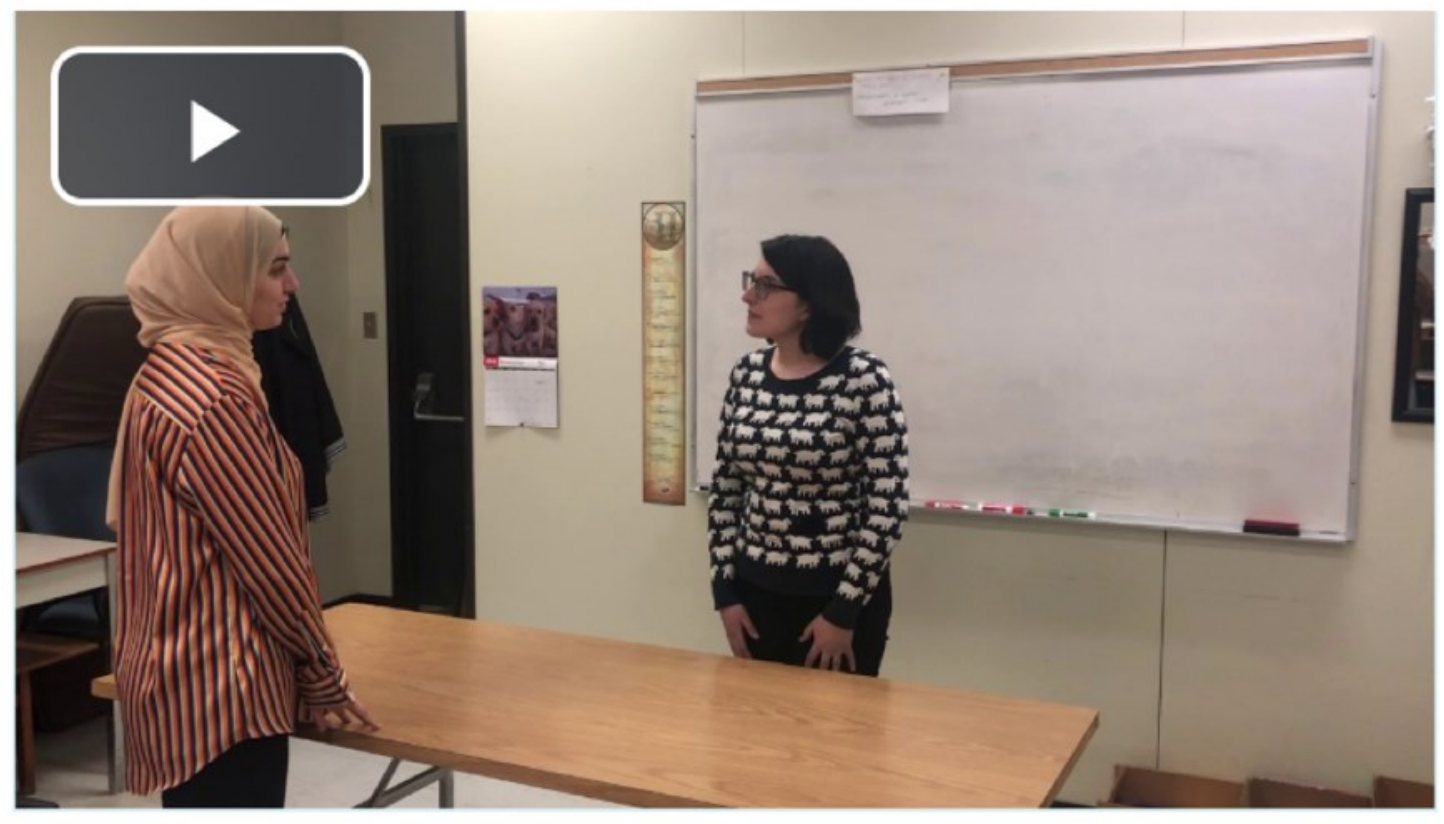

\section{What does Sarah say when she doesn't understand the customer?}

Figure 6. Example of requests language practice

The next task type consisted of scenario-based questions that combined language practice with learners assessing a situation and predicting what could happen next.

Learners were provided with a dialogue of a situation, in which there was a communication breakdown between a customer service representative and a customer, and were then asked to (1) identify what language the customer service representative 
used to try to overcome this breakdown and (2) to assess the effectiveness of the response. Following this, learners were asked to predict what could be said next by the customer service representative. This allowed the learners to apply the input they received in the earlier parts of the module to new situations with increased cognitive demands. Like the first type of tasks, learners were provided with a suggested answer in the feedback and were again told to check the appropriateness and/or accuracy of the response with their teacher. Figure 7 illustrates a scenario question. These questions were the most complex of those in the module and were presented last to ensure the learners were prepared for the demands of the task (Mackey, Ziegler \& Bryfonski, 2016) as well as to allow them to apply the language and knowledge that they had already interacted with earlier in the module to new situations (Schulze \& Liebscher, 2010). 


\section{A customer orders a coffee from Sarah. Sarah wants to check if she understood the customer's order.}

\section{Sarah: Hi there!}

Customer: Can I get a coffee with two creams?

Sarah: You want a coffee with two creams?

Customer: Yes, that's right.

1. What does Sarah say to check if she understood the customer?

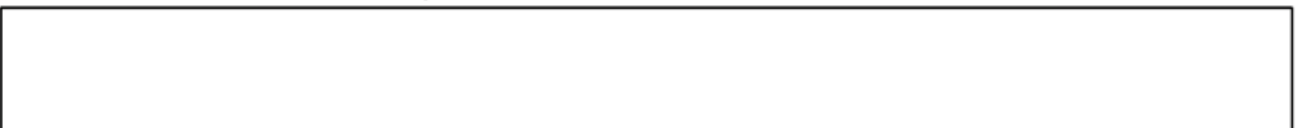

\section{Did saying this help Sarah?}

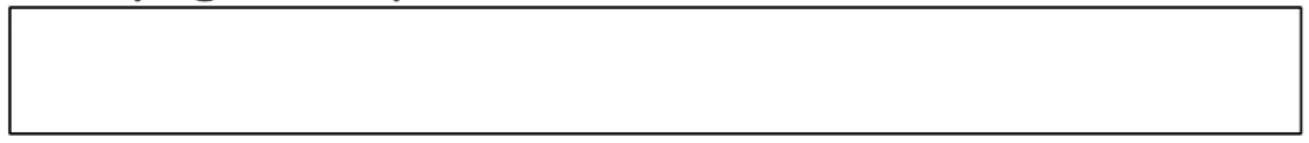

3. What should Sarah say next?

Figure 7. Requests scenario-based task

When developing the scenarios, it was determined that not all scenarios should be resolved "successfully" (i.e., the request used by the customer service representative would not always lead to them understanding what the customer was saying). An example of this can be seen in Figure 8. This was done to increase the level of authenticity of the task and adheres to the TBLT criteria that tasks must be real-world based. Scenarios in which the misunderstanding is not resolved also allow for further critical thinking on the part of the learner. Learners must determine what strategy could be used to further resolve the situation. For example, if the scenario demonstrates that a comprehension check was used, the learner may then decide that a different type of 
request could be used (such as a clarification request) in order to obtain more information. When examining Figure 8, it can be seen that the customer service representative does not understand the customer, and that when she tries to confirm the order with the customer, she is not successful- she misinterprets the customer's order for an English breakfast tea as a request for a breakfast sandwich. However, this is where the scenario ends, requiring learners to determine how to progress and resolve the scenario. This is done first by asking "Did saying this help Sarah?", drawing learner attention to the fact that it did not, and then taking this a step further with the question "What could Sarah say next?", requiring learners to predict what could come next.

A customer asks Sarah for a tea, but Sarah doesn't understand.

Sarah: Hi, how can I help you?

Customer: Can I have an English breakfast tea?

Sarah: Do you want a breakfast sandwich?

Customer: No. I want a tea.

1. What does Sarah say to check if she understands?

2. Did saying this help Sarah?

3. What should Sarah say next?

Figure 8. Unresolved scenario-based task 
It should also be noted that like the prediction tasks in the greetings portion of the module, feedback provided to learners was designed to guide learners without prescribing only one possible answer for the question. The full feedback presented to learners can be seen in Figure 9. The first two questions asked within the scenario task ("What does Sarah say to check if she understood the customer?" and "Did saying this help Sarah?") do have set answers, and as such this feedback provides concrete answers and does not direct the learner to discuss the answer with their teacher. It is the third question ( "What should Sarah say next?") requiring prediction on behalf of the learners that asks them to check their answer with their teacher. Again, the feedback provided learners with a possible answer to the question and instructed learners to discuss their answer with their teacher. 


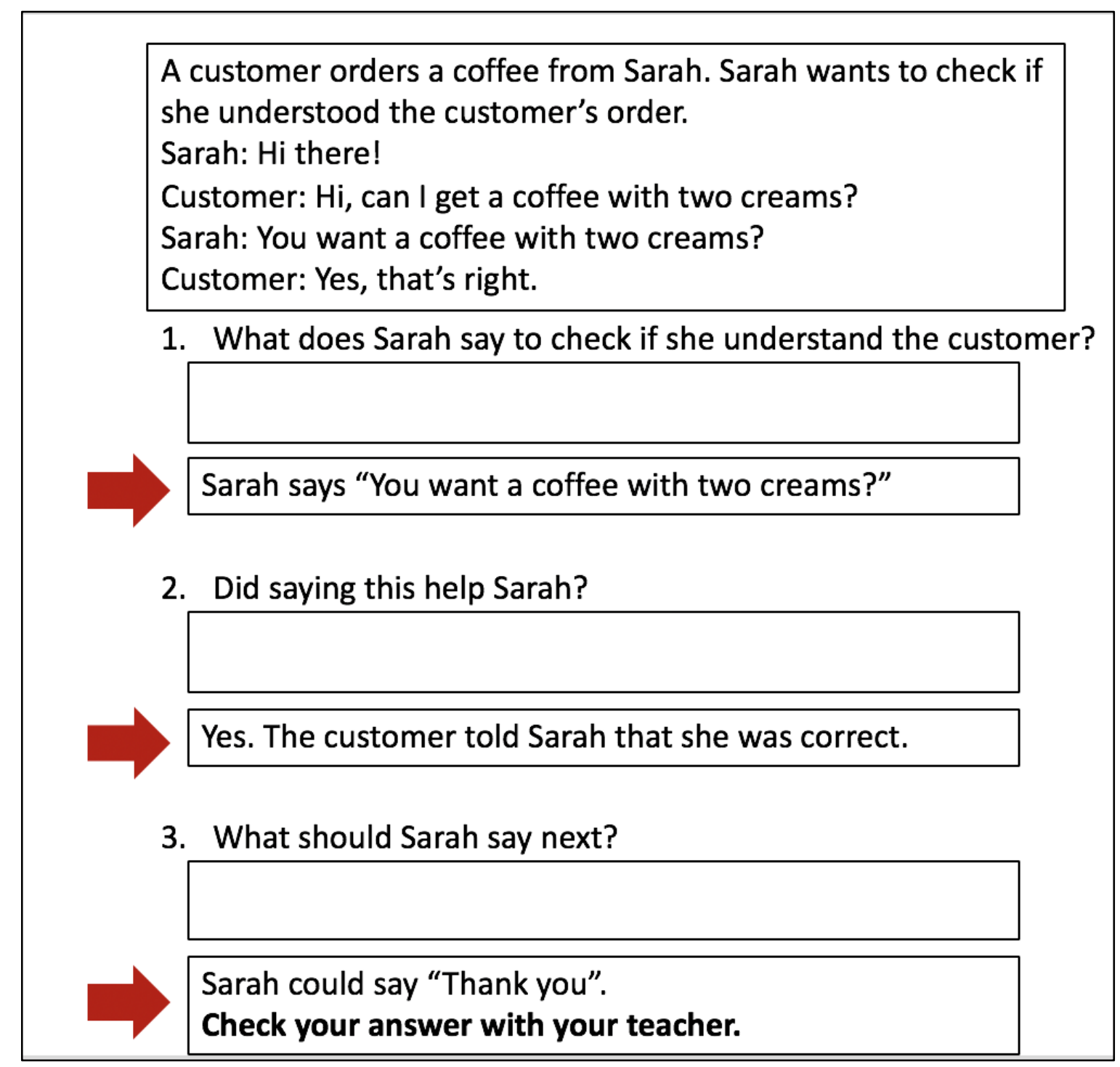

Figure 9. Requests scenario with feedback

To sum up, with regards to the second research question, it can be seen that the use of a technology-mediated TBLT framework appears to allow for the needs of the learners to be integrated into the module. The outcome of the environmental scan, which allowed for learner needs to be identified, and this directly influenced the module design. The module followed the identified themes of greetings and requests, and built tasks around these themes, using language collected in the environmental scan to ensure that 
the tasks remain authentic, meaningful, and reflective of the linguistic needs of the learners. These tasks were designed to be suited for the learners' proficiency level and to provide opportunities for contextualization, language practice, and prediction. Learners are able to build their knowledge of greetings and requests, using a module designed to be supported on a mobile device and incorporating a framework that activates their cognitive and behavioural mechanisms and provides opportunities for improvement incomprehension and pragmatic development (Yanguas, 2012).

\subsection{Research question 3: Perceived module effectiveness by learners and teachers}

\subsubsection{Testing the module}

Testing the module explored the third research question, what is the perceived effectiveness of the module by teachers and learners in the occupation-specific language training program? This question was investigated by feedback collected from both learners and teachers.

The feedback received from the learners was intended to allow not only for the research team to identify the strengths and weaknesses of the module, but to also have those participating in the employment support program have a voice and play an active role regarding their learning. Feedback received from participants can be divided into two different categories: positive feedback (elements learners liked about the module, felt addressed their needs, and that were perceived as effective) and suggestions for modification to the module (elements that challenged learners in a way that was not 
productive but frustrating, and elements that learners felt were missing from the module and that the addition of would increase their perceived effectiveness of the module).

\subsubsection{Positive feedback}

The feedback received from the learners and volunteer teachers during the interviews was positive overall. Feedback was obtained regarding both the module design and usability. In terms of the usability, all the learners and volunteer teachers declared the module easy to use. Similar to past studies which explored the usability of Moodle (e.g., Horvat et al., 2012), the participants found the platform's interface to be clear and straightforward.

The language content of the module was also well-received by the learners and the volunteer teachers. All four learners stated that the language used within the module was an accurate representation of the language that is used in their places of work. Three of the volunteer teachers who had previous work experience in customer service also indicated that they found the language to be reflective of language used in the customer service sector.

The language in the videos was also highly appreciated. The inclusion of videos was considered positive by all participants, and all four volunteer teachers positively commented on the video dialogue. They considered the dialogue to be authentic, relevant to customer service, and easy to follow. One of the volunteer teachers with experience in L2 teaching and material development commented on the pacing and use of contractions within the video. She observed that the pacing matched regular speech and was not slowed down for the learners; she also appreciated that contractions were maintained rather than omitted. She felt that this was a change from other teaching materials she had 
used in the past and praised this inclusion as increasing the authenticity of the language used for the interactions in the videos, specifically stating that the video content accurately represented interactions between customer service representatives and customers.

The phrasing used for the questions that follow the videos was considered by learners to be clear and easy to understand. Two of the volunteer teachers also indicated that they felt the wording of the questions would be easy for the learners to follow and that the questions were appropriate for the proficiency levels of the learners. The proficiency of the learners was also discussed with regards to the length of the module. The module took 45 to 60 minutes to complete with the time varying from learner to learner; higher-level learners generally took less time to complete the module than their lower-level peers. These lower-level learners would at times watch the videos a second time before answering the questions or to confirm their answer. All four learners felt the length of the module was appropriate. Only one volunteer teacher commented on the length of the module, saying that she thought it appropriate and would not make it any longer. Lastly, all four learners stated that they would use the module for workplace language training. One learner in particular discussed her need for this type of module. This learner had struggled with attending face-to-face language classes in the past, and at the time of the study was not paired with a volunteer teacher. She expressed a desire to improve her English skills but was finding it challenging to do so due to work and family commitments. In addition to work and family commitments acting as a barrier to attending language classes, this learner cited transportation as being insufficient to 
maintain attendance at language classes - the commute to classes was too long, and there was not enough time to continue commuting.

\subsubsection{Suggestions for modification}

The participants also made suggestions on how to improve the design of the module and the type of additional content to include. Three recurring suggestions included (1) improving the overall video quality, (2) modifying the feedback timing for the multiple-choice question, and (3) adding a pronunciation component.

Initially, only the greetings portion of the module was piloted. This was to allow for feedback obtained during the piloting and interview process of the greetings portion to influence the development of the requests portion of the module. At this time of piloting, only few suggestions for modification were made. One volunteer teacher who had more experience working with online learning suggested the inclusion of more questions and question types in the finished module. This feedback was considered during the development of the remaining portion of the module. The requests portion of the module uses similar task types to the greetings portion and follows the same principles, but other components not used in the greetings portion were added. For example, the requests portion provides learners with a brief narrative and scenario-based questions, which are not present in the greetings portion of the module.

With regards to the video quality, it should be noted that the videos included in the module and viewed by participants during the piloting were intended to be placeholders. The incorporation of videos has been noted to be one of the benefits of using technology for language learning (Guichon \& McLornan, 2008), and as such, 
videos were selected to be included in the module design. However, one of the important aspects of this study was obtaining feedback from L2 learners and volunteer teachers, and their feedback was desired prior to producing finalized videos. As the feedback regarding the content of the videos was positive, the videos will now be recreated using higher quality equipment. The videos will also be recreated in a customer service setting, thereby increasing their authenticity. In particular, the audio quality was noted as low by both learners and volunteer teachers, who worried that it would be challenging to hear the language used in the videos in nosier public settings. One learner, who piloted the module at her place of work (a grocery store) noted that the video audio quality would be insufficient in a noisy setting and expressed concern over not being able to complete the module at her place of work because of this. This suggested that learners who work in a public or noisy environment may find it challenging to complete the module. This could pose as a limitation to where and when the module could be used. As one of the noted advantages of developing the module using a mobile device is the ability to use it anytime and anywhere, the new videos will need to have high enough audio quality that they can be used in various settings. In addition to improving visual and audio quality, the settings of the videos will be modified to be more reflective of a customer service environment. Again, this was something that was not initially the focus of the videos as they were intended to be placeholders. However, modifying the videos to visually reflect a customer service work environment will increase the authenticity of the videos.

The second suggestion noted by both learners and the volunteer teachers was that the feedback for the module's multiple-choice questions be modified. Moodle does not allow for learners to receive feedback on the module questions until the end of the entire 
module has been completed and submitted. However, Moodle allows learners to receive feedback on the multiple-choice questions individually; each time a learner answers a multiple-choice question, feedback is given about that question. Both learners and volunteer teachers felt that this was slightly confusing and that it negatively impacted the flow of the module. During piloting, one of the learners became briefly stuck on the multiple-choice questions, not realizing that despite having three questions displayed on the screen together, the submit option had to be selected after each question before being able to progress through the module. This learner was then unsure as to why this was not also the case for the remaining question types. Obtaining feedback after each question meant that the flow from question to question was inconsistent. Because of this, the feedback for multiple-choice questions will be modified so that it is provided exclusively upon completion of the module.

The final suggestions concerned the fact that there was no explicit opportunities for pronunciation practice within the module. This was of particular concern to the learners, with three of the four learners answering that they would like a pronunciation component when asked if they felt that there was anything missing from the module. To fulfill this request, existing scholar-approved online pronunciation tools will be incorporated into the module as resources for learners. The two pronunciation tools that will be added are YouGlish (YouGlish, n.d.) and English Accent Coach (Thompson, 2012). YouGlish allows for learners to search for English words or phrases, which they can then hear being pronounced. This is done through a connection with YouTube, and all words and phrases are presented to the learner as a YouTube video. YouGlish provides language that is spoken in the real world in context (YouGlish, n.d.). English 
Accent Coach, in turn, allows for learners to practice their pronunciation of English consonants and vowels through brief lessons on the International Phonetic Alphabet (IPA) and through online games. English Accent Coach has been developed using pronunciation teaching research, and, like the module developed here, is meant to be used as a supplement to, rather than replacement for, face-to-face learning (Thompson, 2012).

While the majority of feedback obtained by participants was integrated into the module, certain elements were not possible to modify. For example, a common observation was that there was no opportunity for learners to practice their speaking skills through the module. At the time of writing this thesis, the addition of a speaking component was not possible due limitations with the software. The version of Moodle used to develop the module is somewhat limited in terms of the addition of components such as plug-ins, which could allow for students to record themselves and create opportunities for speaking. While this is presently a limitation, there has been some interest in acquiring a more advanced version of Moodle that could allow for this in the future. These programming limitations are not uncommon with the use of CALL. Conaim (2008) found that the use of technology for enhancing speaking skills is limited and that additional technological advancements are needed in order to target speaking effectively. Kukulska-Hulme and Shield (2008) also found that speaking was often the most challenging skill to incorporate into technology due to the fact that it often requires more detailed programming.

However, while the module itself does not provide students the opportunity to practice their speaking, this could be the focus of the face-to-face sessions. Volunteer teachers can be made aware that students are not given the opportunity to speak using the 
module and could therefore place a larger emphasis on speaking skills when meeting with learners. The input learners receive from the module can be used as a foundation for tasks completed in these sessions. For example, learners could be asked to role play scenarios similar to those present in the module with their teacher. Having the module content reinforce the speaking activities emphasizes the fact that this is a blended curriculum, in which the module and face-to-face sessions are designed to complement each other.

Another type of feedback received during the interviews was regarding the overall appearance of the module. This feedback (obtained from one of the learner participants) suggested that the module use larger font as well as different colours (a white font on a dark coloured background was suggested) in order to increase the readability of the module content. This feedback is important to consider, as Yang (2013) notes that the usability of MALL software is connected to ease of use, including readability.

Currently, design elements such as the font, colour, and layout of the module are limited to the default settings on the version of Moodle used to develop the module. As mentioned previously, the version of Moodle currently used to host the module is the most "basic" version, meaning that some of the customizability that Moodle offers is not available for the module. However, while this is presently the case, this is something that may be modified in the future. In the meantime, learners who find the text difficult to read due to is size could magnify the text using the "zoom in" feature present on most mobile devices. The positive response to the module has resulted in the selection of Moodle for hosting the remaining nine modules required for the larger project being done with the employment support program. The organization that hosts this program has expressed interest in purchasing a more advanced version of Moodle that would have 
greater customizability. This may allow for more visual and design changes to be incorporated at a later date. According to the research that focuses on the use of CALL to enhance speaking skills, video chat software is often used for learners to practice their speaking (this is often done by having two learners or a learner and a teacher as communication partners). The inclusion of existing video chat software could perhaps be incorporated into the design of the module in a similar manner to the pronunciation components (i.e., by directing learners to existing video chat software), but more research would need to be done to explore the benefits of this as well as its place within a technology-mediated task framework. For example, questions that would need to be considered are, what types of tasks could be implemented this way and how would they improve learner speaking skills?

To summarize, when revisiting the third research question, it can be seen that learners and volunteer teachers considered the module to be effective in reaching its design goals and affecting the kind of engagement sought. This can be seen from the fact that learners felt that the language was relevant and reflective of their place of work, and from the fact that they indicated that they would use the module. Volunteer teachers felt that the module was appropriately suited to the learner needs and praised the tasks included in the module, again speaking to its perceived effectiveness. While the module was well perceived overall, suggestions such as the addition of a pronunciation section speak to the fact that there are elements that would continue to improve the perceived effectiveness of the module. These elements can be integrated into the module and should be considered throughout the development of the remaining modules. 


\section{Chapter 5: Conclusion}

\subsection{Introduction}

In conclusion, the results of this study suggest that the overall structure, design, and usability of the module suit the needs of this group of learners and their teachers. The needs analysis allowed for the identification of the linguistic needs of the learners with regards to occupation-specific language, identifying relevant themes for the module: greetings and requests. The needs analysis also allowed for the selection of a platform that fits the needs of the learners with regards to the availability and accessibility of the module, while effectively allowing the use of a technology-mediated framework consisting of tasks that address the language needs of the learners. Finally, the piloting and interview process revealed that the module was well received by both the learners and volunteer teachers participating in the employment support program. The volunteer teachers and learners responded positively and perceived the module as effective. This final section of the thesis explores the pedagogical and research implications of this study, both on the future of the larger project tasked with developing ten workplace language modules and on the learners and teachers participating in the employment support program. The limitations of the project are also discussed along with future research directions.

\subsection{Pedagogical implications}

The immediate pedagogical implications of this study are contextualized within the larger employment support project. As this module was intended to be the first of ten 
modules, the outcome of this study directly influences the development of the remaining modules both in terms of module design and content.

This study explored the needs (both linguistic and technological) of learners engaged in occupation-specific language training in order to determine what linguistic content should be the focus of the module, and to identify an online platform suited to host the module. An environmental scan was done as part of a needs analysis to determine the linguistic needs of the learners, finding that both greetings and requests were a prevalent theme in the workplace. This approach was deemed useful in selecting authentic language reflective of the workplace, and the themes of greetings and requests were well received by learners and their volunteer teachers. Further application of needs analysis and the environmental scan can be used to aid in the selection of themes and content to populate the remaining modules.

The second part of the needs analysis was conducted to select an online platform to host the module. The learners' needs were again analyzed as part of this process. The outcome of this resulted in Moodle being the platform used. This means that the remaining modules will also be hosted on Moodle, suggesting implications for the structure of the modules. The use of Moodle as the host for the first module led to an awareness of the strengths and limitations of this platform, which will need to be considered as materials are developed for the additional modules. The strengths and limitations of the platform also have direct implications on the blended curriculum. For example, Moodle is able to host materials that enhance learners' reading, writing, and listening skills, but is limited in its ability to host materials that focus on speaking. The overall focus of the blended curriculum must consider this (Neumeier, 2005). This means 
that in order for learners to improve across all four skills, speaking will need to be practiced in the face-to-face sessions.

The module structure was also influenced by the implementation of a technologymediated TBLT framework. The results of the study indicated that this was an effective approach. It was well received by learners and volunteer teachers and appears to address learner needs. Therefore, this approach should be carried over into the remaining modules. The use of contextualization, language practice, and prediction should also continue to be included in future modules, although the tasks themselves may differ. Having a variety of tasks is important to prevent learner boredom (Lynch, 2000). Lynch (2000) observes that while there are benefits to having learners complete multiple tasks that address a specific linguistic goal, it is more engaging and interesting for learners if the tasks themselves are not identical.

The framework and the use of Moodle were well received by the learners who may benefit from this approach. Learners who are not easily able to access language training can now receive workplace language support when and where they need it. The fact that Moodle can be used on mobile devices affords learners with the benefits of MALL: flexibility, portability, and accessibility. The application of the task-based framework allows learners to receive language input that is reflective of language that they would encounter at their place of work and ensures that they will have access to language learning that uses authentic and real-world language.

The participating volunteer teachers can, too, benefit from using this module as a way to supplement their face-to-face sessions and to guide the learning of the students they are working with. The latter point is especially poignant in light of these volunteer 
teachers not necessarily having language teaching training and/or experience. This module can be used by the teachers to help guide their sessions, providing support not only for the learners, but also for the teachers themselves. The teachers will be able to view areas that learners may find more challenging and in which they need more support. Long (2005) suggests that while learners should be consulted regarding their linguistic needs, they may not always be able to identify or be aware of some of the challenges they face. Using technology-enabled module statistics, volunteer teachers can review the learners' answers to determine areas that learners need to work on without having to rely on learner awareness of areas in which they need continued practice. An example of this became apparent during the module testing process, in which one volunteer teacher became aware that the learner she was paired with incorrectly used the pronoun "I" and made a note to review this with him in future sessions.

This work has also identified opportunities for additional applied linguistics research. For example, the work conducted in the environmental scan could continue and lead to the development of a customer service language corpus that could be accessed by teachers wanting to develop authentic materials to use with learners working in customer service. Learners can continue to be consulted throughout this process and could have their advice solicited as the development of the future modules progresses.

\subsection{Limitations}

While this study seeks to help learners unable to attend face-to-face language classes by providing online learning, it is still part of a blended curriculum, meaning that while the need to attend face-to-face classes is reduced, learners are still expected to be 
able to attend weekly face-to-face sessions with volunteer teachers. However, the interview process revealed that not all learners are able to attend sessions with volunteer teachers. One learner found that barriers in transportation made it too challenging for her to meet regularly with a volunteer teacher for the three hours a week. While this was not the focus of this study, it does reveal that there are still limitations as to what services learners have access to. While this learner responded positively to the module and stated that she would like to use the module in the future, this learner will not be able to obtain full feedback on module components such as the prediction tasks or scenarios that direct learners to discuss their answer with their teacher. While this is a limitation for the learners, it is not a limitation of this study itself, as a blended learning approach was predetermined by the employment support organization. This study was solely focused on the development and implementation of the outside-the-classroom, online portion of the blended curriculum. However, the barriers faced by learners are still worth noting and could be explored in future research.

An area of CALL research that could be explored to overcome this barrier is the use of video chat systems. CALL research has explored the used of systems such as Skype, which enable individuals to connect face-to-face over distances (Healey, 2016). This may be something to consider in terms of lack of speaking components in the module. For example, this could enable learners to communicate with their volunteer teachers even if they are not able to commute to classes, and could even be used as a manner for learners to communicate with other learners, something which has been shown to help encourage learners and foster a sense of community and overcome feelings of isolation that may be felt as a newcomer to Canada (Shaffir \& Satzewich, 2010). 
Therefore, this could also mitigate some of the social challenges also faced by newcomers.

The software itself also presents additional limitations. Stockwell and Levy (2006) note that no CALL platform is perfect, and that there is no software that is able to do every desired component of L2 learning. One of the limitations of Moodle is its inability to incorporate speaking elements. Given that limitations are always present, it may be beneficial to be involved in the development of the software itself, rather than selecting an existing software and using it as a CALL platform.

Furthermore, the small sample-size of participants is a limitation. A total of eight participants were involved in this study: four language learners and four volunteer teachers. Having a larger number of participants would have resulted in additional feedback regarding module design and content and would have provided a better picture as to how individuals participating in the employment program perceive the module. Participants were invited to participate in this study by program coordinators for the employment support program, with only eight individuals volunteering. This may be because the target population for this module is a population that is already identified to have limited availability due to working varying hours. This made it difficult to arrange for piloting and interview sessions even for those who agreed to participate in the study. This is something that should be considered as the project moves forward, as participants may be needed for future areas of research within the project.

Ideally, it would be informative to compare the findings of this study with face-toface classrooms and their learners and teachers. This is a limitation of the current study and a possible future direction for further work. A comparison of the findings of this 
study could include a comparison of learner needs, the module design, and learner and teacher perceptions regarding learning language for the workplace. As mentioned previously, face-to-face classrooms do offer some workplace training, but it is often general workplace language rather than occupation-specific (Kaushik \& Drolet, 2018). A comparison of the results of this study with face-to-face classes could include a comparison of occupation-specific online modules being used as part of a blended curriculum and workplace language taught in the classroom. This comparison would have provided further insight into the perceived effectiveness of this approach (such as whether it addresses learners' workplace language needs) and could have helped identify the strengths and limitations of the completed module's content and design. This is something that could be explored as part of a follow-up study or as another aspect of the larger project.

\subsection{Future research directions}

As mentioned previously, this module is part of a larger project and is only the first step in a body of research that aims to provide language support to language learners in the workplace. This study is only a small piece of the research that is being conducted within the scope of the project. As this project progresses and the remaining nine modules are developed, more opportunities for future research are emerging. This could include research into what language themes and topics are present in customer service, as well as research into learner motivation. For example, the exploration of language themes and topics used in customer service could be done as part of a corpus linguistics study, while learner motivation could be part of a study exploring the identity and integration of 
newcomers into Canadian society or the Canadian workforce. Other capabilities of CALL could also be integrated into this research and explored for the future of this program. For example, recent CALL research has explored the benefits of gamification in assisting language acquisition. This is often explored from a motivation perspective, with students being more motivated when tasks are presented as a game, which provides a reward upon completion (Reinhardt \& Thorne, 2016). This is something that could be explored through the Moodle plug-ins that allow learners to receive a "trophy" upon completing a module.

The current module also briefly uses a narrative structure to provide contextualization. This format could be followed throughout the remaining module in order to tell a more in-depth story and can again make the modules more cohesive and connected. Learners can become familiar with the specific customer service worker as they learn the language they need and perform various workplace tasks. This is something that can also be considered during the filming of new videos for the module. The customer service representative role in the videos can be filled by one or more individuals for all videos across all ten modules. This could allow for more cohesion as learners progress from one module to the next. Past research has identified a connection between the use of narrative and identity, suggesting that there may be benefits to integrating a narrative reflective of learner experiences and including a character reflective of the learners themselves across the modules (Vásquez, 2012).

Future research could also explore the learners' attitudes and beliefs regarding the module use on a long-term basis, similar to research conducted by Ushioda (2013), which explores the motivational impact of technology on language learning. This could include 
exploring whether or not learners' motivation regarding language learning increases with the use of the module and how this relates to their experiences in the Canadian workforce. An examination of learner motivation is something that could also be explored as part of a comparison of face-to-face and online learning. For example, motivation research could explore whether there are differences in motivation resulting from the different approaches. This is again similar to Ushioda's research, which asked whether the freedom and control students have over their learning when using technology or the fixed nature of face-to-face classes is more motivating to learners.

As the development of the remaining modules progresses and learners are granted access to the modules, a follow-up study exploring learner use of the modules could be conducted. This would allow for patterns of module use to be observed and would provide insight into whether or not learners find the modules useful. For example, Stockwell (2010) found that learners often used MALL when waiting for transportation or appointments. This could be explored with regards to the existing module. An awareness of this has pedagogical implications for both this program and for other programs seeking to provide outside-the-classroom support for language learners. Furthermore, follow-up interviews could be conducted with learners to determine whether or not they feel the modules address their linguistic needs. While learners responded positively to the module during the piloting, a further investigation after learners have had more time to use the modules may result in changes to the module. These are questions that can be explored throughout the project.

As mentioned previously, volunteer teachers have varying experience teaching English as a second language. While some of the volunteer teachers do have official 
teaching qualifications, some volunteer teachers are completely new to teaching. This suggests that there may be advantages to providing these teachers with teacher training in general as well as that related to technology use in L2 instruction. Research by Hubbard (2008) suggests that teachers are more likely to engage with language learning technology if they receive training. With regards to Moodle, volunteer teachers can be trained on viewing the learner answers to questions in the module. One of the features of Moodle is that teachers can be given access to student responses and submissions. By viewing these submissions, the volunteer teachers can discover areas in which their learners are struggling and in which they may need extra support. This also removes the burden from learners of continually having to show the teachers their mistakes or identify areas that require additional instruction/attention. This both further connects the online learning with the face-to-face sessions and guides the volunteer teachers in developing materials for their sessions.

\subsection{Conclusion}

This thesis described a development of an online module that focused on the greetings and requests used in customer service. It was intended to be the first of ten modules aiming to provide occupation-specific language training for newcomers working in the customer service sector. The module was designed in line with the recommendations put forth by technology-mediated TBLT scholars. These included application of needs analysis that determines both language and technological needs, adoption of the TBLT framework in task design, authentic language use, and consultation with the end users (learners and their teachers) during the design process. While the 
positive feedback obtained from the participants validates the adopted pedagogical approach and the use of technology to support its implementation, the application of needs analysis helped ensure that the language used was authentic and reflective of the language used in customer service. What is more, learner feedback obtained during the module preparation not only ensured that the module contents addressed the needs and desires of the learners it was designed to serve, but that this consultation also allowed the learners to play an active role in their own learning, and in doing so may have helped to promote learner autonomy that can lead to learner independence and empowerment (Fleming \& Walter, 2004).

Overall, the completed module is theory-driven and learner, teacher, and program approved. The application of theory combined with the piloting and assessment of the module from learners and volunteer teachers strengthens the overall integrity of the module design. Ziegler (2016) emphasizes the importance of a theory-driven approach, stating that, with the use of technology for second language learning increasing, there is a need for the use of an implementation approach that is methodologically sound, grounded in existing research, and supported by pedagogy. She indicates that if this type of approach is crucial and that if it is not adopted, then the developmental benefits of using technology for language learning become limited. This highlights the benefits of this pedagogical approach, which has pedagogical implications for the implementation and development of subsequent modules designed to provide outside-the-classroom support to newcomers. In addition to the pedagogical implications, there are research implications that can be explored as this project continues to expand and grow. 


\section{References}

Ally, M., McGreal, R., Schafer, S., Tin, T. \& Cheung, B. (2007). Use of mobile learning technology to train ESL adults. Proceedings of the Sixth International Conference on Mobile Learning, Melbourne. Retrieved from http://hdl.handle.net/2149/2582

Abeysekera, L. \& Dawson, P. (2014). Motivation and cognitive load in the flipped classroom: Definition, rationale and a call for research. Higher Education Research \& Development. 34(1), 1-14.

https://doi.org/10.1080/07294360.2014.934336

Baralt, M. (2013). The impact of cognitive complexity on feedback efficacy during online versus face-to-face tasks. Studies in Second Language Acquisition, 35(4), 689725. https://doi.org/10.1017/S0272263113000429

Barkhuizen, G. (2008). A narrative approach to exploring context in language learning. ELT Journal, 62(3), 231-9. https://doi.org/10.1093/elt/ccm043

Bartel, J. (2018). Teaching soft skills for employability. TESL Canada/Revue TESL du Canada, 35(1), 78-92. https://doi.org/10.18806/tesl.v35i1.1285

Beglar, D. \& Hunt, A. (2002). Implementing task-based language teaching. In J. C. Richards \& W.A. Renandya (Eds.), Methodology in language teaching: An anthology in current practice (pp. 96-106). Cambridge: Cambridge University Press.

Benesch, S. (1996). Needs analysis and curriculum development in EAP: An example of a critical approach. TESOL Quarterly, 30(4), 723-38.

$\underline{\text { http://doi.org/10.2307/3587931 }}$ 
Bikowski, D. \& Kessler, G. (2002). Making the most of discussion boards in the ESL classroom. TESOL Journal, 11(3), 27-31. https://doi.org/10.1002/j.1949$\underline{3533.2002 . t b 00093 . x}$

Blake, R. J. (2007). New trends in using technology in the language curriculum. Annual Review of Applied Linguistics, 27, 76-97. https://doi.org/10.1017/S0267190508070049

Blake, R. J. (2013). Brave new digital classroom: Technology and foreign language learning. Washington: Georgetown University Press.

Blake, R., Wilson, N. L., Cetto, M. \& Pardo-Ballester, C. (2008). Measuring oral proficiency in distance, face-to-face, and blended classrooms. Language Learning \& Technology, 12(3), 114-27. http://dx.doi.org/10125/44158

Bow Valley College. (2015). OER creation for ELL. Retrieved from https://globalaccess.bowvalleycollege.ca/research-development/projectsdevelopment/oer-creation-ell

Bow Valley College. (2018a). Here to help: Workplace communication skills for food services. Retrieved from https://globalaccess.bowvalleycollege.ca/products$\underline{\text { services/here-help-workplace-communication-skills-food-services }}$

Bow Valley College. (2018b). In the workplace: An intermediate integrated skills textbook. Retrieved from https://globalaccess.bowvalleycollege.ca/products$\underline{\text { services/workplace-intermediate-integrated-skills-textbook }}$

Brandl, K. (2005). Are you ready to "Moodle"?. Language Learning and Technology, 9(2), 16-23. http://dx.doi.org/10125/44017 
Canada School of Public Service (2007a). Interface Canada: Book 1. Ottawa: Canada School of Public Service.

Canada School of Public Service (2007b). Interface Canada: Book 2. Ottawa: Canada School of Public Service.

Canada School of Public Service (2007c). Interface Canada: Book 3. Ottawa: Canada School of Public Service.

Canada School of Public Service (2007d). Interface Canada: Book 4. Ottawa: Canada School of Public Service.

Canada School of Public Service. (2007e). Interface Canada: Book 5. Ottawa: Canada School of Public Service.

Canada School of Public Service. (2007f). Interface Canada: Book 6. Ottawa: Canada School of Public Service.

Canada School of Public Service. (2007g). Interface Canada: Book 7. Ottawa: Canada School of Public Service.

Canada School of Public Service. (2007h). Interface Canada: Book 8. Ottawa: Canada School of Public Service.

Centre for Canadian Language Benchmarks. (2012). Canadian language benchmarks: English as a second language for adults. Ottawa: Ministry of Citizenship and Immigration. Retrieved from https://www.canada.ca/content/dam/ircc/migration/ircc/english/pdf/pub/languagebenchmarks.pdf

Chapelle, C. (2001). Computer applications in second language acquisition: Foundations for teaching, testing, and research. Cambridge: Cambridge University Press. 
Chapelle, C. (2005). CALICO at centre stage: Our emerging rights and responsibilities. CALICO Journal, 23(1), 5-15. http://dx.doi.org/10.1558/cj.v23i1.5-15

Chen, X. (2013). Tablets for informal language learning: Student usage and attitudes. Language learning and technology, 17(1), 20-36. http://dx.doi.org/10125/24503

Cook, J. (2015). Negotiation for meaning and feedback among second language learners. Journal of Language Teaching and Research, 6(2), 250-57. http://dx.doi.org/10.17507/jltr.0602.02

Coniam, D. (2008). Evaluating the language resources of chatbots for their potential in English as a second language learning. ReCALL, 20(1), 99-117. https://doi.org/10.1017/S0958344008000815

Colpaert, J. (2004). From courseware to coursewear?. Computer Assisted Language Learning, 17(3-4), 261-6. https://doi.org/10.1080/0958822042000319575

Costello, E. (2014). Opening up to open source: Looking at how Moodle was adopted in higher education. Open Learning: The Journal of Open, Distance and e-Learning, 28(3), 187-200. https://doi.org/10.1080/02680513.2013.856289

Dörnyei, Z. (2007). Research methods in applied linguistics. Oxford: Oxford University Press.

Doughty, C. J. \& Long, M. H., (2003). Optimal psycholinguistic environments for distance foreign language learning. Language Learning \& Technology, 7(3), 5080. https://doi.org/10125/25214

Douglas, S.R. \& Kim, M. (2014). Task-based language teaching and English for academic purposes: An investigation into instructor perceptions and practice in 
the Canadian context. TESL Canada Journal, 31(8), 1-22.

https://doi.org/10.18806/tesl.v31i0.1184

Egbert, J. Paulus T. M. \& Nakamichi, Y. (2002). The impact of CALL instruction on classroom computer foundation for rethinking technology in teacher education. Language Learning and Technology, 6(3), 108-126. https://doi.org/10125/25179

Egbert, J. \& Yang, Y. D. (2004). Mediating the digital divide in CALL classrooms: Promoting effective language tasks in limited technology contexts. $\operatorname{Re} C A L L$, 16(2), 280-291. https://doi.org/10.1017/S0958344004000321

Ellis, R. (2003). Task-based learning and teaching. Oxford: Oxford University Press.

Ellis, R. (2005). Understanding second language acquisition. Oxford: Oxford University Press.

Ellis, N. C. \& Bogart, P. S. H. (2007). Speech and language technology in education: The perspective from SLA research and practice. Proceedings of the SlaTE Workshop on Speech and Language Technology in Education, Farmington, PA.

English at Work (2018). English at Work. Retrieved from https://www.eaweese.ca/

Farr, F. \& Murray, T. (2016). Introduction. In F. Farr \& T. Murray (Eds.), The Routledge handbook of language learning and technology (pp. 1-5). New York: Routledge.

Fleming, D. \& Walter, P. (2004). Linking teacher professionalism and learner autonomy through experiential learning and task design [Special issue]. TESL Canada Journal/Revue TESL du Canada, 4, 58-72. https://doi.org/10.18806/tesl.v0i0.1040

George, U. (2002). A needs-based model for settlement service delivery for newcomers to Canada. International Social Work, 45(4), 465-80. https://doi.org/10.1177/00208728020450041001 
Godwin-Jones, R. (2011). Emerging technologies: Mobile apps for language learning. Language Learning and Technology, 15(2), 2-11. http://dx.doi.org/10125/44244

Gonulal, T. \& Loewen, S. (2018). Scaffolding technique. In J.I. Liontas (Ed.), The TESOL encyclopedia of English language teaching (pp. 1-5). Hoboken, NJ: John Wiley \& Sons.

González-Lloret (2014). The need for needs analysis in technology-mediated TBLT. In M. González-Lloret \& L. Ortega (Eds.), Technology-mediated TBLT: Researching technology and tasks (pp. 23-50). Amsterdam: John Benjamins Publishing Company.

González-Lloret, M. \& Ortega, L. (2014). Towards technology-mediated TBLT. In M. González-Lloret \& L. Ortega (Eds.), Technology-mediated TBLT: Researching technology and tasks (pp. 1-22). Amsterdam: John Benjamins Publishing Company.

Government of Canada. (2018). Language learning products catalogue of the Canada school of public service. Retrieved from http://publications.gc.ca/site/eng/search/LanguageLearningProductsCatalogue.htm $\underline{1}$

Government of Saskatchewan. (2019). Language Training. Retrieved from https://www.saskatchewan.ca/residents/moving-to-saskatchewan/immigrating-tosaskatchewan/language-training-and-settlement-services/language-training

Grgurovic, M. (2011). Blended learning in an ESL class: A case study. CALICO Journal, 29(1), 100-17. https://doi.org/10.11139/cj.29.1.100-117 
Guichon N. \& McLornan, S. (2008). The effects of multimodality on L2 learners:

Implications for CALL resource design. System, 36(1), 85-93.

https://doi.org/10.1016/j.system.2007.11.005

Hampel, R. \& Hauck, M. (2004). Towards an effective use of audio conferencing in distance education courses. Language Learning \& Technology, 8(1), 66-82. $\underline{\text { http://doi.org/10125/25230 }}$

Healey, D. (2016). Language learning and technology: Past, present and future. In F. Farr \& T. Murray (Eds.), The Routledge handbook of language learning and technology (pp. 9-23). New York: Routledge.

Hong, K. H. \& Samimy, K. K. (2013). The Influence of L2 Teachers' Use of CALL Modes on Language Learners' Reactions to Blended Learning. CALICO Journal, 27(2), 328-48. http://doi.org/10.11139/cj.27.2.328-348

Horvat, A., Dobrota, M., Krsmanovic, M., \& Cudanov, M. (2012). Student perception of Moodle learning management system: A satisfaction and significance analysis. Interactive Learning Environments, 23(4), 515-27. https://doi.org/10.1080/10494820.2013.788033

Hubbard, P. (2006). Evaluating CALL Software. In L. Ducate \& N. Arnold (Eds.), Calling on CALL: From theory and research to new directions in foreign language teaching (pp. 1-26). San Marcos: CALICO Monograph Series.

Hubbard, P. (2008). CALL and the future of teacher education. CALICO Journal, 25(2), 175-88. https://doi.org/10.1558/cj.v25i2.175-188 
Hsu, L. (2011). English as a foreign language learners' perception of mobile assisted language learning: A cross-national study. Computer Assisted Language Learning, 26(3), 197-213. https://doi.org/10.1080/09588221.2011.649485

Hunter, D. (2017). Activity. ELT Journal, 71(4), 516-8. https://doi.org/10.1093/elt/ccx030

Immigration, Refugees and Citizenship Canada. (2019). Newcomer services. Retrieved from https://www.canada.ca/en/immigration-refugeescitizenship/campaigns/newcomers.html?utm_campaign=not$\underline{\text { applicable\&utm_medium }=\text { vanity-url\&utm_source }=\text { canada-ca_newcomerservices }}$

Jamieson, J., Chapelle, C. A. \& Preiss, S. (2004). Putting principles into practice. $\operatorname{ReCALL,~16(2),~396-415.~}$

Jingwel, T. (2013). The research on blended earning of ESL based on Moodle platform. Literature and Language, 6(2), 30-4. https://doi.org/10.3968/j.sl1.1923156320130602.3612

Kaushik, V. \& Drolet, J. (2018). Settlement and integration of needs of skilled immigrants in Canada. Social Sciences, 7(76), 1-14. https://doi.org/10.3390/socsci7050076

Kim, H. (2008). Beyond motivation: ESL/EFL teachers' perceptions of the role of computers. CALICO Journal, 25(2), 241-59. https://doi.org/10.1558/cj.v25i2.241259

Kim, H. \& Kwon, Y. (2012). Exploring smartphone applications for effective mobileassisted language learning. Multimedia-Assisted Language Learning, 15(1), 3257. 
Kukulska-Hulme, A. (2007). Mobile usability in educational contexts: What have we learnt?. International Review of Research n Open and Distance Learning, 8(2), 116. https://doi.org/10.19173/irrodl.v8i2.356

Kukulska-Hulme, A. \& Shield, L. (2008). An overview of mobile assisted language learning: From content delivery to supported collaboration and interaction. ReCALL, 20(3), 271-89. https://doi.org/10.1017/S0958344008000335

Kustec, S. (2012). The role of migrant labour supply in the Canadian labour market. Ottawa: Citizenship and Immigration Canada. Retrieved from https://www.canada.ca/content/dam/ircc/migration/ircc/english/resources/research /2012-migrant/documents/pdf/migrant2012-eng.pdf

Lamb, M. (2004). Integrative motivation in a globalizing world. System, 32(1), 3-19. https://doi.org/10.1016/j.system.2003.04.002

Lai, C. \& Li, G. (2011). Technology and task-based language teaching: A critical review. CALICO Journal, 28(2), 498-521. https://doi.org/ 10.11139/cj.28.2.498-521

Lasagabaster, D. \& Sierra, J. M. (2010). Students' evaluation of CALL software programs. Educational Media International, 40(3-4), 293-304. https://doi.org/10.1080/0952398032000113211

Lee, H. G. \& Egbert, J. (2016). Language learning and technology in varied learning contexts. In F. Farr \& T. Murray (Eds.), The Routledge handbook of language learning and technology (pp. 9-23). New York: Routledge.

Levy, M. (2009). Technologies in use for second language learning. The Modern Language Journal, 93, 769-782. https://doi.org/10.1111/j.1540$\underline{4781.2009 .00972 . x}$ 
Levy, M. \& Stockwell, G. (2006). Theory. CALL Dimensions (pp. 110-41). Mahwah, New Jersey: Lawrence Erlbaum Associates.

Lochhead, C \& Mackenzie, P. (2005). Integrating newcomers into the Canadian labour market. Canadian Issues, 103-6.

Long, M. H. (1983). Linguistic and conversational adjustments to non-native speakers. Studies in Second Language Acquisition, 5(2), 177-93. https://doi.org/10.1017/S0272263100004848

Long, M. H. (2005). Second language needs analysis. Cambridge: Cambridge University Press.

Long, M. H. (2015). Second language acquisition and task-based language teaching. Hoboken, NJ: John Wiley \& Sons.

Long, M. H. (2016). In defense of tasks and TBLT: Nonissues and real issues. Annual Review of Applied Linguistics, 36, 5-33. https://doi.org/10.1017/S0267190515000057

Long, M. H. \& Porter, P. A. (1985). Group work, interlanguage talk and second language acquisition, TESOL Quarterly, 19(2), 207-28. https://doi.org/10.2307/3586827

Lu, M. (2008). Effectiveness of vocabulary learning via mobile phone. Journal of Computer Assisted Learning, 24, 515-525. https://doi.org/10.1111/j.1365$\underline{2729.2008 .00289 . x}$

Lynch, T., \& McLean, J. (2000). Exploring the benefits of task repetition and recycling for language learning. Language Teaching Research, 4(3), 421-50. https://doi.org/10.1177/136216880000400303 
Mackey, A., Ziegler, N. \& Bryfonski, L. (2016). From SLA research on interaction to TBLT materials. In B. Tomlinson (Ed.), SLA Research and Materials Development for Language Learning (pp. 103-17). New York: Routledge.

Miyazoe, T. \& Anderson, T. (2009). Learning outcomes and students' perceptions of online writing: Simultaneous implementation of a forum, blog, and wiki in an EFL blended learning setting. System, 38(2), 185-99. https://doi.org/10.1016/j.system.2010.03.006

Murphy, J. (2010). The settlement \& integration needs of immigrants: A literature review. Ottawa: Citizenship and Immigration Canada. Retrieved from https://olipplio.ca/knowledge-base/wp-content/uploads/2013/03/Olip-Review-of-LiteratureFinal-EN.pdf

Murray, D. (2005). Technologies for second language literacy. Annual Review of Applied Linguistics, 25, 188-201. https://doi.org/10.1017/S0267190505000103

Neumeier, P. (2005). A closer look at blended learning-parameters for designing a blended learning environment for language teaching and learning. ReCALL, 17(2), 163-78. http://doi.org/10.1017/S0958344005000224

Norquest College. (2010a). Common ground: Guide to English in the workplace (Phase 2). Retrieved from https://www.norquest.ca/research-innovation/colbourneinstitute-for-inclusive-leadership/projects/completed-projects/common-groundguide-to-english-in-the-workplace-(phase-2).aspx

Norquest College. (2010b). Common ground: Guide to English in the workplace (Phase 3). Retrieved from https://www.norquest.ca/research-innovation/colbourne- 
institute-for-inclusive-leadership/projects/completed-projects/common-groundguide-to-english-in-the-workplace-(phase-2).aspx

Norquest College. (2018a). LINC works Curriculum. Retrieved from https://www.norquest.ca/research-innovation/research/research-projects-atnorquest/linc-works/curriculum-materials.aspx

Norquest College. (2018b). Online workplace integration language resources. Retrieved from https://www.norquest.ca/research-innovation/colbourne-institute-forinclusive-leadership/projects/completed-projects/online-workplace-integrationlanguage-resources-(owls).aspx

Nunan, D. (1989). Designing Tasks for the Communicative Classroom. Cambridge: Cambridge University Press.

O'Bryan, A. \& Hegelheimer, V. (2007). Integrating CALL into the classroom: The role of podcasting in an ESL listening strategies course. ReCALL, 19(2), 162-80. http://doi.org/10.1017/S0958344007000523

Ontario Council of Agencies Serving Immigrants. (2017). What different kinds of ESL programs are available? Retrieved from https://settlement.org/ontario/education/english-as-a-second-language-esl/esl-foradults/what-different-kinds-of-esl-programs-are-available/

Payne, J. S. \& Whitney, P. J. (2002). Developing L2 oral proficiency through synchronous CMC: Output, working memory and interlanguage development. CALICO Journal, 20(1), 7-32. http://doi.org/10.1558/cj.v20i1.7-32

Pellettieri, J. (2000). Negotiation in cyberspace: The role of chatting in the development of grammatical competence. In M. Warschauer \& R. Kern (Eds.), Network-based 
language teaching: Concepts and practice (pp. 59-86). Cambridge: Cambridge University Press.

Plonsky, L. \& Ziegler, N. (2016). The CALL-SLA interface: Insights from a secondorder synthesis. Language Learning \& Technology, 20(2), 17-37. https://doi.org/10125/44459

Plews, J. L. \& Zhao, K. (2010). Tinkering with tasks knows no bounds: ESL teacher adaptations of of task-based language-teaching. TESL Canada Journal, 28(1), 4159. https://doi.org/10.18806/tesl.v28i1.1059

Rahimi, M. \& Miri, S. S. (2014). The impact of mobile dictionary use on language learning. Procedia Social and Behavioural Sciences, 9, 1469-74. https://doi.org/10.1016/j.sbspro.2014.03.567

Reinhardt, J. \& Thorne, S. (2016). Metaphors for digital games and language learning. In F. Farr \& T. Murray (Eds.), The Routledge handbook of language learning and technology (pp. 415-30). New York: Routledge.

Reitz, J. G. (2007). Immigrant employment success in Canada, part 1: Individual and contextual cases. International Migration and Integration, 8, 11-36. http://doi.org/10.1007/s12134-007-0001-4

Robinson, P. (2001). Task complexity, task difficulty, and task production: Exploring interactions in a componential framework. Applied Linguistics, 22(1), 27-57. https://doi.org/10.1093/applin/22.1.27

Roby, W. B. (2004). Technology in the service of foreign language learning: The case of the language laboratory. In D. H. Jonassen (Ed.), Handbook of research on 
educational communications and technology (pp. 523-44). Mahwah, NJ: Lawrence Erlbaum Associates.

Schmidt, R. (2001). Attention. In P. Robinson (Ed.), Cognition and second language acquisition (pp. 3-32). Cambridge: Cambridge University Press.

Schulze, M. \& Liebscher, G. (2010). Going in cycles: Courseware and material development for written communication. CALICO Journal, 27(3), 554-63. https://doi.org/10.11139/cj.27.3.554-563

Schwienhorst, K. (2008). Learner autonomy and CALL environments. New York: Routledge.

Shaffir, W. \& Satzewich, V. (2010). The informal settlement sector: Broadening the lens to understand newcomer integration in Hamilton. Hamilton: Hamilton Integration Partnership.

Stockwell, G. (2007). A review of technology choice for teaching language skills and areas in the CALL literature. ReCALL, 19(2), 105-120. http://doi.org/10.1017/S0958344007000225

Stockwell, G. (2010). Using mobile phones for vocabulary activities: Examining the effect of the platform. Language Learning and Technology, 14(2), 95-110. $\underline{\text { http://dx.doi.org/10125/44216 }}$

S.U.C.C.E.S.S. (2019). Immigration Settlement \& Integration Program. Retrieved from: https://www.successbc.ca/eng/services/settlement-services/immigrant-settlementintegration-program/\#ccw

Sykes, J. M. (2014). TBLT and synthetic immersive environments: What can in-game task restarts tell us about design and implementation? In M. González-Lloret \& L. 
Ortega (Eds.), Technology-mediated TBLT: Researching technology and tasks (pp. 149-82). Amsterdam: John Benjamins Publishing Company.

Thompson, R. (2012). English Accent Coach. Retrieved from

https://www.englishaccentcoach.com/

Thornbury, S. (2006). An A-Z of ELT. Oxford: Macmillan.

Thorne, K. (2003). Blended learning: How to integrate online and traditional learning. London: Kogan Page Limited.

Tomlinson, B. (2012). Materials development for language learning and teaching. Language Learning, 45(2), 143-79. https://doi.org/10.1017/S0261444811000528

Toyoda, E. \& Harrison, R. (2002). Categorization of text chat communication between learners and native speakers of Japanese. Language Learning Technology, 6(1), 82-99. https://doi.org/10125/25144

Ushioda, E. (2013). Motivation matters in mobile language learning: A brief commentary. Language Learning and Technology, 17(3), 1-5. $\underline{\text { http://doi.org/10125/44333 }}$

Willis, J. (1996). A framework for task-based learning. Essex, UK: Longman Publishing. Willis, D., \& Willis, J. (2007). Doing task-based teaching. Oxford: Oxford University Press.

Yang, J. (2013). Mobile assisted language learning: Review of the recent applications of emerging mobile technologies. English Language Training, 6(7), 19-25. $\underline{\text { https://doi.org/10.5539/elt.v6n7p19 }}$ 
Yanguas, I. (2012) Task-based oral computer-mediated communication and L2 vocabulary acquisition. CALICO Journal, 29, 507-31. https://doi.org/10.11139/cj.29.3.507-531

YouGlish. (n.d.). Retrieved from https://youglish.com/

Vásquez, C. (2011). TESOL, teacher identity, and the need for "small story" research. TESOL Quarterly, 45(3), 535-45. https://doi.org/10.5054/tq.2011.256800

Ziegler, N. (2016). Taking technology to task: Technology-mediated TBLT, performance and production. Annual Review of Applied Linguistics, 36, 136-63. https://oi.org/10.1017/S026719051600003 


\section{Appendices}

\section{Appendix A}

\section{Data collected from textbooks and online resources}

\section{Greetings Data}

\begin{tabular}{|l|l|}
\hline Phrase & Number of Occurrences \\
\hline Hello. & 65 \\
\hline Hi. & 48 \\
\hline Thank you. & 36 \\
\hline Good morning. & 23 \\
\hline Hello, what can I do for you? & 12 \\
\hline Bye! & 12 \\
\hline Goodbye. & 9 \\
\hline Hi, nice to meet you. & 9 \\
\hline See you later. & 8 \\
\hline Hi there. & 7 \\
\hline How's it going? & 6 \\
\hline Hello, how do you do? & 6 \\
\hline Hello, how are you? & 5 \\
\hline How're you doing? & 5 \\
\hline How may I help you? & 5 \\
\hline Hello, how may I help you? & 4 \\
\hline Thank you for your time. & 4 \\
\hline See you tomorrow & 4 \\
\hline Hello, pleased to meet you. & 4 \\
\hline Hi, how are you? & 3 \\
\hline Have a good day! & 3 \\
\hline Hi, thanks for meeting with me today. & 3 \\
\hline Hello, this is Bob speaking (on the phone) & 2 \\
\hline Hi, beautiful day isn't it? & 2 \\
\hline Hello, how can I help you? & 2 \\
\hline See you. & 2 \\
\hline Have a nice weekend. & 2 \\
\hline O.K. Bye. & 2 \\
\hline Thanks, you too. & 2 \\
\hline Fine thanks, and you? & 2 \\
\hline Hi, how're things? & 2 \\
\hline Let me know if you need anything. & 2 \\
\hline Hello, how are you today? & 2 \\
\hline Hello, my name is & 2 \\
\hline Hello, I'm & 2 \\
\hline & \\
\hline
\end{tabular}




\begin{tabular}{|l|l|}
\hline Hello, welcome to & 2 \\
\hline Hi, can I take your order? & 2 \\
\hline Hi, how are you? Are you ready to order? & 2 \\
\hline Hello, can I help who's next? & 2 \\
\hline Hi, what can I make for you? & 2 \\
\hline Hello, I'm & 2 \\
\hline Hi, my name is & 2 \\
\hline Isn't is beautiful today? & 2 \\
\hline Cold enough for you? & 2 \\
\hline Hey, working hard? & 2 \\
\hline Hello. Is it busy today? & 2 \\
\hline No problem. See you later. & 2 \\
\hline Is that everything? & 2 \\
\hline Thank you for your time. & 2 \\
\hline Thanks, enjoy the rest of your day! & 2 \\
\hline I hope to see you again soon. & 2 \\
\hline Hi, can I order $?$ & 2 \\
\hline Hi, can I have $?$ & 2 \\
\hline Hi, can I get & 2 \\
\hline Hello, could I get & 2 \\
\hline Hi, can I please $?$ & 2 \\
\hline Hi, I'd like & 2 \\
\hline Have a good night. & 1 \\
\hline Have a good evening. & 1 \\
\hline Hello, how's your day going? & 1 \\
\hline Good evening/morning/afternoon sir/madam. & 1 \\
\hline Goodbye sir/madam. It was a pleasure helping & 1 \\
\hline you. & \\
\hline Hi, how're you today? & 1 \\
\hline Oh, hello. How are you? & 1 \\
\hline Come again. & 1 \\
\hline See ya! & 1 \\
\hline See you soon! & 1 \\
\hline Hello, who's next? & 1 \\
\hline Good morning. Can I help you? & 1 \\
\hline Mornin'! & 1 \\
\hline Goodbye, happy holidays! & 1 \\
\hline Have a good night! & 1 \\
\hline Hope you have a great holiday! & 1 \\
\hline Hello! Happy New Year! & 1 \\
\hline Hi, happy Easter! & 1 \\
\hline Good morning, happy National Aboriginal Day! & 1 \\
\hline Happy Paschal! & 1 \\
\hline Merry Christmas! & 1 \\
\hline Blessed Ramadan! & \\
\hline & \\
\hline
\end{tabular}


Happy Diwali!

Happy Hanukkah!

1

\section{Requests Data}

\begin{tabular}{|c|c|}
\hline Phrases & Number of Occurrences \\
\hline I'm sorry, I don't understand. & 6 \\
\hline What did you say? & 6 \\
\hline I'm not sure about... & 6 \\
\hline Would it be possible for you to repeat that? & 6 \\
\hline Would you ? ? & 6 \\
\hline Would you mind...? & 5 \\
\hline What is & 5 \\
\hline Pardon me, but can you say that again? & 4 \\
\hline , anything else? & 4 \\
\hline What kind of $\quad$ do you want? & 4 \\
\hline What do you mean by _ ? ? & 4 \\
\hline What did you want me to do? & 4 \\
\hline I was wondering if you could... & 4 \\
\hline Could you (please)...? & 3 \\
\hline You're asking...? & 3 \\
\hline Could you repeat that? & 3 \\
\hline Excuse me, but I didn't understand & 3 \\
\hline I didn't hear you. & 3 \\
\hline So that's... & 3 \\
\hline Ok, I got.. & 3 \\
\hline Just to check, that's & 3 \\
\hline Just to be clear, you want to...? & 3 \\
\hline What do you mean? I don't understand. & 3 \\
\hline Can you slow down? & 3 \\
\hline Could you please ? ? & 3 \\
\hline Can you...? & 2 \\
\hline Would it be OK if...? & 2 \\
\hline Is it possible to...? & 2 \\
\hline I was wondering if you could tell me...? & 2 \\
\hline Could you say that again please? & 2 \\
\hline Can you spell that for me? & 2 \\
\hline Could you repeat that, please? & 2 \\
\hline I'm not sure what you mean. & 2 \\
\hline Here's what I got.... & 2 \\
\hline Did you mean & 2 \\
\hline What do you mean by & 2 \\
\hline Can you explain & 2 \\
\hline I'm not sure about & 2 \\
\hline I'm not sure what you're saying. & 2 \\
\hline
\end{tabular}




\begin{tabular}{|l|l|}
\hline How do I ? & 2 \\
\hline Could you please ? & 2 \\
\hline So, you're asking me...? & 2 \\
\hline Ok, I understand, & 2 \\
\hline I think I know what you mean, you want...? & 2 \\
\hline Ok, right? & 2 \\
\hline Did I do okay? & 2 \\
\hline Could you maybe say that again? & 2 \\
\hline Can you way that more slowly? & 2 \\
\hline Is it or ? & 2 \\
\hline Do you mind... & 2 \\
\hline Why are you here? & 2 \\
\hline Oh, you want...? & 1 \\
\hline I didn't catch that. Can you repeat it? & 1 \\
\hline It sounds like you're asking... & 1 \\
\hline I think I heard you say.... & 1 \\
\hline Could you explain that to me again? & 1 \\
\hline I'm sorry but I don't understand what you're talking \\
about. & 1 \\
\hline So, you're asking me.... & \\
\hline You're asking about _? & 1 \\
\hline So, where are we? & 1 \\
\hline So, what do you need? & 1 \\
\hline I need you to repeat that. & 1 \\
\hline Who should I talk to? & 1 \\
\hline Is this right? & 1 \\
\hline Are these the right fries? & 1 \\
\hline So, you think I should... & 1 \\
\hline You want me to $?$ & 1 \\
\hline Not sure I follow you there. & 1 \\
\hline Mind repeating yourself? & 1 \\
\hline Can you please ? & 1 \\
\hline Would you please ? & 1 \\
\hline Could you show me? & 1 \\
\hline If it's not too much trouble, could you repeat that? & 1 \\
\hline & 1 \\
\hline & \\
\hline
\end{tabular}




\section{Appendix B}

\section{Data from workplace observations}

\section{Observation 1}

- Learner was providing coupons and samples of "Dark Chocolate Almond Milk" and "Creamy Cashew Milk"

- Learner greeted almost every customer that walked by

- Approximately 30 customers stopped by for a sample

\begin{tabular}{|l|l|l|}
\hline Utterance & Context of Use & Type of Utterance \\
\hline $\begin{array}{l}\text { Hi, would you like } \\
\text { to try... }\end{array}$ & $\begin{array}{l}\text { Said to customers in the store } \\
\text { as the walk by the sampling } \\
\text { station. }\end{array}$ & Greeting \\
\hline $\begin{array}{l}\text { Hi, would you like } \\
\text { to... }\end{array}$ & $\begin{array}{l}\text { Said to customers in the store } \\
\text { as the walk by the sampling } \\
\text { station. }\end{array}$ & Greeting \\
\hline Hi! & $\begin{array}{l}\text { Said to customers in the store } \\
\text { as the walk by the sampling } \\
\text { station. }\end{array}$ & Greeting \\
\hline It's down over here. & $\begin{array}{l}\text { A response to a customer who } \\
\text { asked where she could get the } \\
\text { product in the store. }\end{array}$ & $\begin{array}{l}\text { Responding to Question/ } \\
\text { Giving Directions }\end{array}$ \\
\hline I have chocolate... & $\begin{array}{l}\text { Said to a customer who wanted } \\
\text { a sample to inform customer of } \\
\text { what they could sample. }\end{array}$ & Providing \\
Options/Explanation \\
\hline Another day. & $\begin{array}{l}\text { A response to a customer that } \\
\text { joked about coming back } \\
\text { another time for a sample. }\end{array}$ & Small talk/ Humour \\
\hline No problem. & $\begin{array}{l}\text { A customer said thank you after } \\
\text { receiving a sample }\end{array}$ & Ending Interaction \\
\hline It's a milk. & $\begin{array}{l}\text { Informing a customer who } \\
\text { approached the table that the } \\
\text { product being offered is a type } \\
\text { of milk. }\end{array}$ & Description \\
\hline For three month. & $\begin{array}{l}\text { Chatting with a customer about } \\
\text { the new kinds of milk. }\end{array}$ & Small talk \\
\hline Do you like it? & $\begin{array}{l}\text { Asking a customer if they liked } \\
\text { the sample they were given. }\end{array}$ & Small talk \\
\hline It's a new one & $\begin{array}{l}\text { Informing a customer that the } \\
\text { product being sampled is new. }\end{array}$ & Description \\
\hline $\begin{array}{l}\text { Would you like to } \\
\text { get this one or this } \\
\text { one? }\end{array}$ & $\begin{array}{l}\text { is given the correct sample. } \\
\text { inging sure that the customer }\end{array}$ & Clarifican Request \\
\hline
\end{tabular}




\begin{tabular}{|c|c|c|}
\hline $\begin{array}{l}\text { Would you like to } \\
\text { taste it? }\end{array}$ & $\begin{array}{l}\text { Asking a customer who took a } \\
\text { coupon if they would also like a } \\
\text { sample }\end{array}$ & Request \\
\hline $\begin{array}{l}\text { Would you like to } \\
\text { get creamy cashew? }\end{array}$ & Offering a customer a sample. & Confirmation Request \\
\hline $\begin{array}{l}\text { Would you like to } \\
\text { get a coupon? }\end{array}$ & Offering a customer a coupon. & Request \\
\hline You're welcome & $\begin{array}{l}\text { A customer said thank you after } \\
\text { receiving a sample }\end{array}$ & Ending Discourse/Interaction \\
\hline I have two flavours & $\begin{array}{l}\text { Informing a customer that there } \\
\text { are two flavours at the sample } \\
\text { station. }\end{array}$ & Description \\
\hline $\begin{array}{l}\text { I have two: dark } \\
\text { chocolate and } \\
\text { creamy cashew }\end{array}$ & $\begin{array}{l}\text { Informing a customer that there } \\
\text { are two flavours at the sample } \\
\text { station. }\end{array}$ & Description \\
\hline Which one? & $\begin{array}{l}\text { Making sure that the customer } \\
\text { is given the correct sample. }\end{array}$ & Clarification Request \\
\hline $\begin{array}{l}\text { We have another } \\
\text { flavour- } \\
\text { unsweetened. }\end{array}$ & $\begin{array}{l}\text { Informing a customer about } \\
\text { other flavours of milk for sale } \\
\text { at Loblaws }\end{array}$ & Explanation \\
\hline $\begin{array}{l}\text { You can throw it. } \\
\text { (pointing to trash } \\
\text { can) }\end{array}$ & $\begin{array}{l}\text { Showing a customer that didn't } \\
\text { like the sample }\end{array}$ & Giving directions \\
\hline $\begin{array}{l}\text { A lot. (pointing to } \\
\text { label) }\end{array}$ & $\begin{array}{l}\text { A customer asked about the } \\
\text { amount of sugar in the milk }\end{array}$ & Response \\
\hline Okay. & $\begin{array}{l}\text { A customer said they aren't } \\
\text { interested }\end{array}$ & Response \\
\hline They have this one. & $\begin{array}{l}\text { A customer complained about } \\
\text { there not being an unsweetened } \\
\text { version in stock }\end{array}$ & $\begin{array}{l}\text { Clarification due to } \\
\text { misunderstanding }\end{array}$ \\
\hline It's a new product & $\begin{array}{l}\text { Customer repeated complaint } \\
\text { and this was the response }\end{array}$ & $\begin{array}{l}\text { Clarification due to } \\
\text { misunderstanding }\end{array}$ \\
\hline I don't have it. & $\begin{array}{l}\text { Customer repeated complaint a } \\
\text { third time and this was the } \\
\text { response }\end{array}$ & $\begin{array}{l}\text { Clarification due to } \\
\text { misunderstanding }\end{array}$ \\
\hline I don't know, sorry. & $\begin{array}{l}\text { Customer repeated complaint a } \\
\text { fourth time and this was the } \\
\text { response }\end{array}$ & $\begin{array}{l}\text { End of } \\
\text { misunderstanding/Ending } \\
\text { discourse }\end{array}$ \\
\hline Yeah, sure. & $\begin{array}{l}\text { A customer asked if they could } \\
\text { try a sample }\end{array}$ & Response \\
\hline Over here. & $\begin{array}{l}\text { Showing a customer where they } \\
\text { can buy the milk }\end{array}$ & Giving Directions \\
\hline Have a good day. & $\begin{array}{l}\text { A customer finished their } \\
\text { sample }\end{array}$ & Ending Discourse/Interaction \\
\hline Bye. & $\begin{array}{l}\text { A customer finished their } \\
\text { sample }\end{array}$ & Ending Discourse/Interaction \\
\hline
\end{tabular}




\begin{tabular}{|l|l|l|}
\hline $\begin{array}{l}\text { You can save one } \\
\text { dollars. }\end{array}$ & $\begin{array}{l}\text { A customer was reading a } \\
\text { coupon }\end{array}$ & Response/Explanation \\
\hline No, I can show you. & $\begin{array}{l}\text { Redirecting a customer to the } \\
\text { correct aisle to purchase the } \\
\text { milk being sampled. }\end{array}$ & Response/Giving directions \\
\hline
\end{tabular}

\section{Observation 2}

- Learner was providing coupons and samples of chocolate

- Learner greeted almost every customer that walked by

- Approximately 10 customers stopped by for a sample

\begin{tabular}{|l|l|l|}
\hline Utterance & Context & Type of Function \\
\hline $\begin{array}{l}\text { Hi! How are } \\
\text { like Would you } \\
\text { chocolate wafer. } \\
\text { They are by } \\
\text { Kagi. I have two } \\
\text { kinds: classic } \\
\text { and dark } \\
\text { chocolate. }\end{array}$ & $\begin{array}{l}\text { Said customers to get their } \\
\text { attention }\end{array}$ & $\begin{array}{l}\text { Greeting/Introducing/Describing } \\
\text { the product }\end{array}$ \\
\hline $\begin{array}{l}\text { Hi. How are } \\
\text { you? }\end{array}$ & $\begin{array}{l}\text { Said to customers as they } \\
\text { walked by. }\end{array}$ & \\
\hline $\begin{array}{l}\text { They have them } \\
\text { just behind you. } \\
\text { In this aisle. }\end{array}$ & Indicating where the & Greeting \\
\hline $\begin{array}{l}\text { Hey, how are } \\
\text { you? So, we're } \\
\text { sampling Kagi } \\
\text { chocolate } \\
\text { wafers. }\end{array}$ & $\begin{array}{l}\text { Said to customers to get their } \\
\text { attention }\end{array}$ & Greeting \\
\hline Here you go. & Giving customers the sample. & Closing interaction \\
\hline $\begin{array}{l}\text { Hi, would you } \\
\text { like to try a } \\
\text { chocolate wafer? }\end{array}$ & $\begin{array}{l}\text { Said to customers to get their } \\
\text { attention }\end{array}$ & Greeting \\
\hline
\end{tabular}

\section{Observation 3}

- Learners worked in a bakery as cashiers

- Learners were also required to answer the phone to fill bakery orders

- Three employees were observed 
- Coworkers speak Arabic to each other (all employees are Arabic-speakers)

- Also served Arabic speaking customers

- Approximately 20 customers were served (8 of these customers were Arabic speaking)

- Only the English-speaking interactions were documented

\begin{tabular}{|c|c|c|}
\hline Utterance & \begin{tabular}{|l} 
Context \\
\end{tabular} & Function \\
\hline $\begin{array}{l}\text { Would you like } \\
\text { receipt? }\end{array}$ & $\begin{array}{l}\text { Said to customers after they had } \\
\text { paid }\end{array}$ & $\begin{array}{l}\text { Closing interaction with } \\
\text { customer }\end{array}$ \\
\hline $\begin{array}{l}\text { Would you like } \\
\text { coffee? }\end{array}$ & $\begin{array}{l}\text { Said to customers who chose to } \\
\text { eat at the bakery }\end{array}$ & \\
\hline One coffee? & $\begin{array}{l}\text { Said to confirm a customer's } \\
\text { order }\end{array}$ & Comprehension check \\
\hline Cake? & $\begin{array}{l}\text { Said to confirm a customer's } \\
\text { order }\end{array}$ & Comprehension check \\
\hline What kind of cake? & $\begin{array}{l}\text { Said to clarify a customer's } \\
\text { order }\end{array}$ & Clarification request \\
\hline It's called $\mathrm{xxxx}$ & $\begin{array}{l}\text { Providing the Arabic name of a } \\
\text { baked good to a customer }\end{array}$ & Giving information \\
\hline It's Parisian & $\begin{array}{l}\text { Describing a baked good to a } \\
\text { customer }\end{array}$ & Description \\
\hline $\begin{array}{l}\text { If you Google, } \\
\text { you'll see it }\end{array}$ & $\begin{array}{l}\text { Informing customer about a } \\
\text { baked good }\end{array}$ & Giving information \\
\hline There you go & $\begin{array}{l}\text { Repeated when giving } \\
\text { purchases to customers }\end{array}$ & $\begin{array}{l}\text { Closing interaction with } \\
\text { customer }\end{array}$ \\
\hline This my sister & $\begin{array}{l}\text { Informing a customer that the } \\
\text { employees were related }\end{array}$ & Small talk \\
\hline One medium cake? & $\begin{array}{l}\text { Said to confirm a customer's } \\
\text { order }\end{array}$ & Comprehension check \\
\hline $\begin{array}{l}\text { I like this kind of } \\
\text { cake }\end{array}$ & $\begin{array}{l}\text { Recommending a cake to a } \\
\text { customer }\end{array}$ & Making suggestions \\
\hline Hi, how are you? & $\begin{array}{l}\text { Said to customers as they } \\
\text { entered the bakery }\end{array}$ & Greeting \\
\hline $\begin{array}{l}\text { Hi, how can I help } \\
\text { you? }\end{array}$ & $\begin{array}{l}\text { Said to customers as they } \\
\text { entered the bakery }\end{array}$ & Greeting \\
\hline How many? & Clarifying a customer's order & Clarification request \\
\hline In a box? & Clarifying a customer's order & Clarification request \\
\hline $\begin{array}{l}\text { Do you want to try } \\
\text { it? }\end{array}$ & $\begin{array}{l}\text { Checking if a customer asked } \\
\text { for a sample }\end{array}$ & Confirmation request \\
\hline This one? & Confirming a customer's order & Confirmation request \\
\hline A bit more? & Confirming a customer's order & Confirmation request \\
\hline That's good & $\begin{array}{l}\text { Recommending a baked good to } \\
\text { a customer. }\end{array}$ & Making suggestions \\
\hline
\end{tabular}




\begin{tabular}{|c|c|c|}
\hline A bag? & $\begin{array}{l}\text { Confirming that the customer } \\
\text { wanted a bag }\end{array}$ & Comprehension check \\
\hline Yeah? & $\begin{array}{l}\text { Confirming what a customer } \\
\text { asked for }\end{array}$ & Confirmation request \\
\hline $\begin{array}{l}\text { You want your } \\
\text { receipt? }\end{array}$ & $\begin{array}{l}\text { Confirming what the customer } \\
\text { wants }\end{array}$ & Confirmation request \\
\hline Have a good day. & Finishing serving a customer. & Closing \\
\hline Here you go & Finishing serving a customer & Closing \\
\hline Okay. & $\begin{array}{l}\text { Response to a customer placing } \\
\text { an order }\end{array}$ & Response \\
\hline Sure. & $\begin{array}{l}\text { Response to a customer placing } \\
\text { an order }\end{array}$ & Response \\
\hline Which one? & $\begin{array}{l}\text { Clarifying what a customer } \\
\text { ordered }\end{array}$ & Clarification request \\
\hline Anything else? & $\begin{array}{l}\text { Asking if a customer would like } \\
\text { to order more baked goods }\end{array}$ & \\
\hline Thank you. & Finishing serving a customer & Ending Discourse/Interaction \\
\hline $\begin{array}{l}\text { How is the } \\
\text { weather? }\end{array}$ & $\begin{array}{l}\text { Talking about the bad weather } \\
\text { with a customer }\end{array}$ & Small Talk \\
\hline It is not a nice day. & $\begin{array}{l}\text { Talking about the bad weather } \\
\text { with a customer }\end{array}$ & Small talk \\
\hline Hi! & $\begin{array}{l}\text { Said to customers as they enter } \\
\text { the bakery }\end{array}$ & Greetings \\
\hline Sorry? & $\begin{array}{l}\text { Misunderstood what a customer } \\
\text { said }\end{array}$ & Clarification request \\
\hline What kind of nut? & $\begin{array}{l}\text { Repeated back to a customer to } \\
\text { confirm understanding }\end{array}$ & Comprehension check \\
\hline Walnut & $\begin{array}{l}\text { Responding to a customer's } \\
\text { question about the ingredients in } \\
\text { a baked good. }\end{array}$ & Response \\
\hline Yeah, pistachio & $\begin{array}{l}\text { Responding to a customer's } \\
\text { question about the ingredients in } \\
\text { a baked good. }\end{array}$ & Response \\
\hline Two each? & $\begin{array}{l}\text { Confirming what a customer } \\
\text { ordered }\end{array}$ & Comprehension check \\
\hline
\end{tabular}




\section{Appendix C \\ Guiding interview questions}

The following questions were used to guide the interviews, but the interviews were semistructured in nature. This means that the overall structure of the interview was flexible and that there was open-ended discussion.

1. What did you think about the module?

2. What did you think about the software?

3. How easy or difficult it was to use?

4. What parts did you find most useful?

5. What parts did you find least useful?

6. Is there anything that you would add to the module?

7. Is there anything you would remove from the module?

8. Additional comments/concerns. 


\section{Appendix D}

\section{Ethics clearance}

\section{G. Carleton \\ Canada's Capital University}

Office of Research Ethics

5110 Human Computer Interaction Bldg | 1125 Colonel By Drive

Ottawa, Ontario K1S 5B6

613-520-2600 Ext: 2517

ethics@carleton.ca

\section{CERTIFICATION OF INSTITUTIONAL ETHICS CLEARANCE}

The Carleton University Research Ethics Board-A (CUREB-A) has granted ethics clearance for the research project described below and research may now proceed. CUREB-A is constituted and operates in compliance with the Tri-Council Policy Statement: Ethical Conduct for Research Involving Humans (TCPS2).

Ethics Protocol Clearance ID: Project \# 109032

Project Team Members: Gillian McLellan (Primary Investigator)

Dr. Eva Kartchava (Research Supervisor)

Michael Rodgers (Research Supervisor)

Project Title: Designing a Computer-Assisted Language Learning Module for Second Language Learners in the Customer Service Sector[Gillian McLellan]

Funding Source (If applicable):

\begin{tabular}{|c|c|c|c|}
\hline $\begin{array}{l}\text { Awards } \\
\text { File No }\end{array}$ & Title & Status & \\
\hline 109011 & $\begin{array}{l}\text { Designing a Computer Assisted Language Learning (CALL) } \\
\text { Module for Second Language Learners in the Customer Service } \\
\text { Sector }\end{array}$ & Active & $\begin{array}{l}\text { CORIS } \\
\text { Awards }\end{array}$ \\
\hline
\end{tabular}

Effective: July 04, 2018

Expires: July 31, 2019.

Please ensure the study clearance number is prominently placed in all recruitment and consent materials: CUREB-A Clearance \# 109032.

\section{Restrictions:}


This certification is subject to the following conditions:

1. Clearance is granted only for the research and purposes described in the application.

2. Any modification to the approved research must be submitted to CUREB-A via a Change to Protocol Form. All changes must be cleared prior to the continuance of the research.

3. An Annual Status Report for the renewal of ethics clearance must be submitted and cleared by the renewal date listed above. Failure to submit the Annual Status Report will result in the closure of the file.If funding is associated, funds will be frozen.

4. A closure request must be sent to CUREB-A when the research is complete or terminated.

5. Should any participant suffer adversely from their participation in the project you are required to report the matter to CUREB-A.

Failure to conduct the research in accordance with the principles of the Tri-Council Policy Statement: Ethical Conduct for Research Involving Humans 2 nd edition and the Carleton University Policies and Procedures for the Ethical Conduct of Research may result in the suspension or termination of the research project.

Upon reasonable request, it is the policy of CUREB, for cleared protocols, to release the name of the PI, the title of the project, and the date of clearance and any renewal(s).

Please contact the Research Compliance Coordinators, at ethics@carleton.ca, if you have any questions.

CLEARED BY:

Date: July 04, 2018

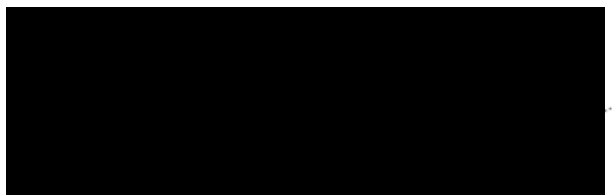

Bernadette Campbell, PhD, Chair, CUREB-A

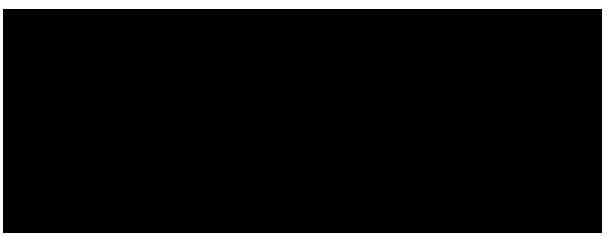

Andy Adler, PhD, Vice-Chair, CUREB-A 